\title{
Geomorfologia e arquitetura deposicional de uma planície de cordões lito- râneos na margem NE da Lagoa dos Quadros, RS, Brasil
}

\author{
Volney Junior Borges de BITENCOURT ${ }^{1}$, Sérgio Rebello DILLENBURG ${ }^{2}$, Eduardo Guimarães \\ BARBOZA², Rogério Portantiollo MANZOLLI ${ }^{3} \&$ Felipe CARON ${ }^{4}$
}

(1) Programa de Pós-graduação em Geociências, Instituto de Geociências, Universidade Federal do Rio Grande do Sul. Av. Bento Gonçalves, 9500, CEP 91.540-000, Porto Alegre, RS, Brasil. E-mail: volneybitencourt@gmail.com, rogeriomanzolli@gmail.com.

(2) Centro de Estudos de Geologia Costeira e Oceânica, Instituto de Geociências, Universidade Federal do Rio Grande do Sul. Av. Bento Gonçalves, 9500, CEP 91.540-000, Porto Alegre, RS, Brasil. E-mail: sergio.dillenburg@ufrgs.br, eduardo.barboza@ufrgs.br.

(3) Research group in Environmental Management and Sustainability. Faculty of Environmental Sciences. Universidad De La Costa. Calle 58 \#55-66, 080002, Barranquilla, Atlántico, Colombia.

(4) Universidade Federal do Pampa, Campus Caçapava do Sul. Av. Pedro Anunciação, 111, Vila Batista, CEP 96.570-000, Caçapava do Sul, RS, Brasil. E-mail: felipecaron@unipampa.edu.br.

Recebido em 01/2015. Aceito para publicação em 07/2016.

Versão online publicada em 26/08/2016 (www.pesquisasemgeociencias.ufrgs.br)

\begin{abstract}
Resumo- Cordões litorâneos regressivos do tipo dunas frontais (foredune ridges) e do tipo praia (beach ridges) são elementos morfológicos muito comuns em margens de lagoas e lagunas costeiras, embora ainda pouco estudados. Neste trabalho, são apresentados resultados do estudo de uma planície de cordões litorâneos regressivos arenosos que se formou na margem NE da Lagoa dos Quadros, no litoral norte do Rio Grande do Sul. A partir da análise de fotografias aéreas, levantamentos altimétricos, perfis de georadar (GPR), testemunhos de sondagem e amostras superficiais, foram investigadas a morfologia da planície de cordões e o arcabouço estratigráfico de seus respectivos depósitos sedimentares. A planície é composta por 20 cordões contínuos e semi-contínuos, de baixa amplitude e espaçados de 5 a $50 \mathrm{~m}$. Sobre uma fácies basal de fundo lagunar que se formou aproximadamente entre 7 e $6 \mathrm{ka}$, desenvolveu-se uma sequência regressiva de modo agradacional e progradacional composta por depósitos de antepraia, de pós-praia/face de praia, dunas frontais e depósitos de leque de sobrelavagem. Dunas transgressivas adentrando na lagoa a partir da barreira holocênica IV (barreira de Curumim) podem ter sido uma importante fonte de areia para o desenvolvimento da planície de cordões.

Palavras-chave: GPR, cordão de praia, cordão de duna frontal, sequência regressiva, barreira complexa, lagoa costeira.
\end{abstract}

\begin{abstract}
GEOMORPHOLOGY AND DEPOSITIONAL ARCHITECTURE OF A STRANDPLAIN AT THE NE MARGIN OF QUADROS LAGOON, RS, BRAZIL. Foredune ridges and beach ridges are morphological elements largely present in coastal lakes and coastal lagoons. However, it still requires further studies. This paper presents results of a prograding strandplain (sand ridge plain) developed at the NE margin of Quadros Lagoon, in the northern littoral of Rio Grande do Sul. Aerial photographs analysis, topographic surveying, GPR records, soundings and surface samples allowed to study the morphology of the strandplain and the stratigraphic framework of their respective sedimentary deposits. The strandplain comprises 20 continuous and semi-continuous ridges, of low amplitude and spaced 5 to $50 \mathrm{~m}$. A regressive sequence comprising deposits of shoreface, backshore/beachface, foredunes and washover fans was developed aggradacionaly and proggradacionaly over a basal facies of a lagoon bottom, between the last 7 to 6 ky. Transgressive dunefields from the Holocene barrier IV (Curumim barrier) to Quadros Lagoon was probably an important source of sand for the strandplain development.
\end{abstract}

Key-words: GPR, beach ridge, foredune ridge, regressive sequence, complex barrier, coastal lagoon

\section{Introdução}

Cordões litorâneos são feições morfológicas comuns de regiões costeiras de caráter progra- dacional-regressivo e agradacional (sensu Roy et al., 1994). São frequentes em costas quaternárias deposicionais, dominadas por ondas e com regime de micro e mesomaré, que apresentam um alto suprimento de sedimento (principalmente na fração 
areia) e baixo gradiente (Curray et al., 1969; Carter, 1986, Hesp, 1999, 2006; Otvos, 2000; Woodroffe, 2002; Anthony, 2008). Conforme Woods \& Leahy (1983), ocorrem tanto em costas oceânicas quanto nas margens de corpos aquosos confinados ou semiconfinados.

Diversos estudos com enfoque na evolução, estratigrafia (arquitetura interna) e morfologia superficial de cordões litorâneos de costas oceânicas foram realizados na última década, sobretudo, por meio da integração de dados geofísicos de alta resolução, análises geomorfológicas e testemunhos de sondagens (e.g. Neal et al., 2002; Goy et al., 2003; Johnston et al., 2007; Tamura et al., 2008; Barboza et al., 2009, 2011a, 2011b, 2013; Bennett et al., 2009; Hesp et al., 2009; Nielsen \& Johanessen, 2009; Caron et al., 2010; Clemmensen \& Nielsen, 2010; Dillenburg et al., 2011; Tamura, 2012; Bendixen et al., 2013; Choi et al., 2013; Lima et al., 2013; Mauz et al., 2013; Rocha et al., 2013; Biancini da Silva et al., 2014; Billy et al., 2014).

Componentes frequentes em grande parte dos corpos lagunares e lacustres da porção emersa da Bacia de Pelotas, cordões litorâneos regressivos do tipo praia (beach ridges) e do tipo duna frontal (foredune ridges) ainda recebem pouca atenção em comparação com seus análogos de costas oceânicas. Todavia, alguns trabalhos relativos a cordões litorâneos foram conduzidos em corpos lagunares e lacustres da Planície Costeira do Rio Grande do Sul - PCRS (e.g. Manzolli, 2011; Tomazelli et al., 2011; Santos et al., 2015).

Este trabalho tem por objetivo caracterizar, com dados de superfície e de subsuperfície, a morfologia superficial e a arquitetura deposicional de uma planície de cordões de litorâneos regressivos que preenchem um embaiamento na margem $\mathrm{NE}$ da Lagoa dos Quadros, situada na porção norte do litoral do Rio Grande do Sul (RS).

\section{2 Área, materiais e métodos}

\section{1 Área}

Parte da margem nordeste da Lagoa dos Quadros, localizada no município de Capão da Canoa (RS), porção setentrional da PCRS, apresenta uma planície de cordões arenosos regressivos com forma de meia-lua, orientação NW-SE e área de $2,9 \mathrm{~km}^{2}$, com comprimento e largura máxima de 4,1 km e 1,1 km respectivamente (Fig. 1 e $2 \mathrm{~A}$ ).

A Lagoa dos Quadros, segunda maior lagoa do sistema lagunares do Litoral Norte do RS (Tomazelli \& Villwock, 1991), está inserida na retaguarda da barreira holocênica (barreira IV), setor I da
PCRS segundo Dillenburg et al. (2000), delimitada a oeste pelas escarpas da Serra Geral e a leste pelo Oceano Atlântico. A geologia local e os depósitos sedimentares adjacentes à área em apreço foram pesquisados e mapeados por Villwock (1984), Horn Filho (1988), Hesp et al. (2005, 2007), Dillenburg et al. (2006), Dillenburg \& Barboza (2009). Além do mais, Cwik (1999) e Meyer et al. (2005, 2006) realizaram importantes estudos em relação a aspectos físicos, sedimentológicos e evolutivos da Lagoa dos Quadros.

A regressão da barreira holocênica em sua porção anexa à Lagoa dos Quadros - barreira de Curumim (Fig. 2B) - aconteceu em duas fases distintas, com um importante controle do suprimento de sedimentos e, de forma secundária, pelo lento e progressivo rebaixamento do nível relativo do mar (NRM) ocorrido nos últimos 6 - 5 ka (Dillenburg et al., 2006, 2009): (i)7,1 - 5,5 ka, uma maior taxa de suprimento sedimentar no sistema praial em relação à taxa de elevação do NRM, que resultou em uma regressão normal da barreira, com progradação de cerca de $1 \mathrm{~m} \cdot \mathrm{ano}^{-1}$, mesmo com o nível relativo do mar em lenta ascensão; (ii) após o nível de mar mais alto da Transgressão Marinha Pós-glacial (TMP), que alcançou entre 2 e $3 \mathrm{~m}$ acima do nível do mar atual, a progradação ocorreu em diferentes taxas, que variaram entre $1,3 \mathrm{~m} \cdot \mathrm{ano}^{-1}(7,1-5,5 \mathrm{ka})$, $0,9 \mathrm{~m} \cdot$ ano $^{-1}(4,5-3,3 \mathrm{ka})$ e $0,2 \mathrm{~m} \cdot$ ano $^{-1}$ de $3,3 \mathrm{ka}$ até o presente; foi influenciada, também, ainda que de forma muito subordinada, pela lenta queda do NRM que se seguiu, ou seja, a progradação passou a se desenvolver com uma parcela de contribuição de uma condição de regressão forçada.

À época do início do desenvolvimento dessa barreira, havia uma grande laguna em sua retaguarda. Com o rebaixamento do nível de base após 6 - $5 \mathrm{ka}$, aliado à descarga de sedimentos oriundos de rios (e.g. rios Maquiné e Três Forquilhas) e da ação eólica, a grande laguna foi então assoreada e segmentada, com o desenvolvimento de feições geomorfológicas arenosas como esporões (spits), esporões recurvados e cordões litorâneos (Villwock \& Tomazelli, 1995; Dillenburg et al., 2009).

0 clima da área de estudo é temperado chuvoso, com meses quentes no verão e frios no inverno, temperatura média de $20^{\circ} \mathrm{C}$, umidade em torno de $84 \%$ e precipitação média de $1322 \mathrm{~mm} \cdot \mathrm{a}^{-1}$ (Hasenack \& Ferraro, 1989). Conforme a classificação de Koppen-Gaiger, o clima é do tipo $C f a$, com precipitações médias entre 1000 - 1500 mm bem distribuídos ao longo do ano (Strahler \& Strahler, 1987). Os padrões de ventos na PCRS são determinados em larga escala pela interação dos Anticiclones do Atlântico Sul e Móvel Polar. Isso resulta em carac- 


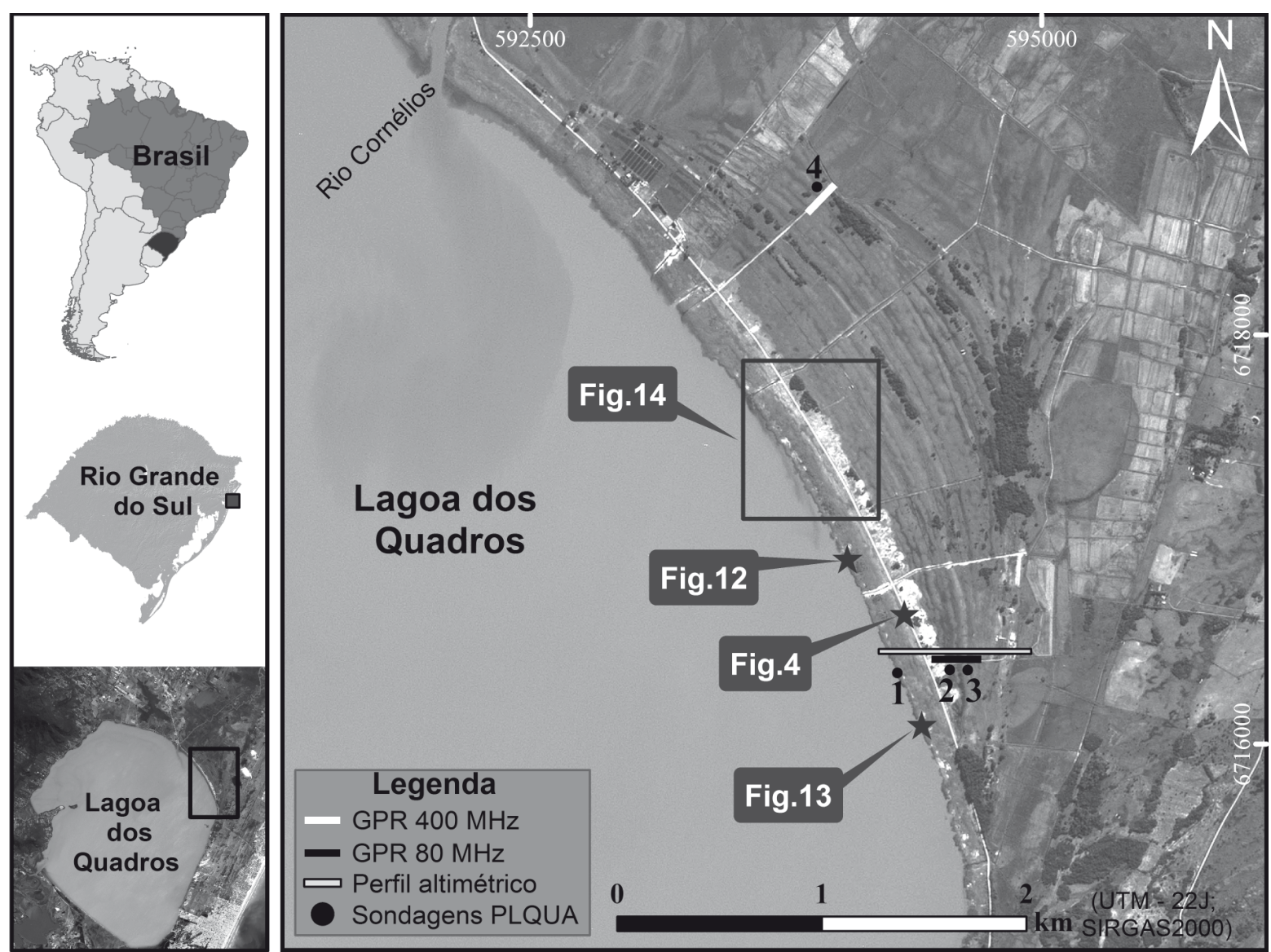

Figura 1. Localização da área de estudo e amostragens realizadas. Levantamentos de GPR, com antenas nas frequências centrais de $400 \mathrm{MHz}$ e $80 \mathrm{MHz}$, sondagens vibro-coring e percussão e perfil altimétrico selecionado. As estrelas situam o ponto geográfico das fotografias das figuras 4, 12 e 13. 0 retângulo delimita a espacialização da figura 14. Imagem do satélite SPOT-5 (banda pancromática).

terísticas sazonais, na qual os meses mais quentes (primavera e verão) têm ventos mais frequentes oriundos do quadrante $\mathrm{NE}$, enquanto nos meses mais frios (outono e inverno), ventos do quadrante S e SW são mais comuns, normalmente associados à passagem de sistemas frontais antárticos (Schwarzbold \& Schafer, 1984; Medeiros, 1992; Tomazelli, 1993). Entretanto, a presença da Serra Geral modifica consideravelmente os padrões de ventos na área de estudo, podendo diminuir a potencialidade destes de NE (Tomazelli et al., 2008).

\subsection{Materiais e métodos}

Neste estudo foram coletadas informações superficiais e de subsuperfície (Fig. 1). Dados geomorfológicos em planta da área foram obtidos a partir de análises comparativas de imagens de satélite e fotografias aéreas históricas e altimetria de detalhe. Para a caracterização do pacote sedimentar em subsuperfície foram realizadas perfilagem geofísica com uso de Radar de Penetração no Solo (Grounding Penetrating Radar - GPR ou georadar) e coletas de testemunhos de sondagens rasos. Datações por ${ }^{14} \mathrm{C}$ permitiram estimar o estágio do iní- cio do desenvolvimento da planície de cordões, e a modelagem de ondas e análise de ventos propiciaram inferir as possíveis condições fluidodinâmicas envolvidas à época de sua gênese.

\subsubsection{Registros geofísicos de GPR}

Os levantamentos geofísicos de GPR/georadar seguiram os procedimentos adotados por Barboza et al. (2009, 2014). Foi utilizado um console da empresa GSSI ${ }^{\mathrm{TM}}$ (Geophysical Survey Systems, Inc.), modelo SIR-3000 com antenas nas frequências centrais de 80 e $400 \mathrm{MHz}$. 0 alinhamento para aquisição dos dados foi perpendicular aos cordões (dip) com arranjo common off set. Foi utilizada uma constante dielétrica de 25 na frequência de $400 \mathrm{MHz}$ e de 15 na frequência de $80 \mathrm{MHz}$.

Os dados foram processados nos programas RADAN $^{\mathrm{TM}} 6.6$ e Reflex-Win ${ }^{\odot}$ para a aplicação de filtros limitantes de frequência, remoção de ruídos contínuos (background removal), ganho de sinal e correções de constante de aquisição (profundidade). As interpretações das radarfácies seguiram o método da sismoestratigrafia adaptado de Neal (2004), baseado nas terminações (onlap, toplap, 
downlap e truncamentos) e no padrão e geometria dos refletores (Mitchum Jr. et al., 1977; Vail, 1987).

\subsubsection{Levantamento altimétrico de detalhe}

A altimetria em detalhe da área consistiu no reconhecimento das altitudes do relevo da planície de cordões da margem NE da lagoa. As medidas foram realizadas no topo e base (pé) do cordão e nas respectivas cavas em relação ao NRM, que se refere ao Datum de Imbituba (nível médio do mar no Porto de Imbituba/SC entre 1949 e 1957) do Sistema Geodésico Brasileiro (SGB). Foi utilizado um Sistema de Posicionamento Global Geodésico (GNSS Geodésico) da empresa Topcon ${ }^{\circledR}$, modelo Hiper L1-L2 com duas antenas e dois coletores FC-250 no modo cinemático. 0 programa Topcon Tools 7.5 foi utilizado para processar os dados, e a conversão das altitudes geométricas para ortométricas foram realizadas com uso do programa MAPGE02015 - Modelo de ondulação geoidal, disponibilizado pelo Instituto Brasileiro de Geografia e Estatística (IBGE).

\subsubsection{Testemunhos de sondagens rasos}

As sondagens foram feitas através dos métodos vibro coring e à percussão. Para tanto, foram utilizados canos de $6 \mathrm{~m}$ de comprimento por 75 mm de diâmetro, de alumínio para vibro coring e de PVC para percussão. No caso das sondagens à percussão, o cano de PVC foi previamente marcado a cada $10 \mathrm{~cm}$ e foi realizada a contagem do número de batidas do peso-batente $(28 \mathrm{~kg}$ em queda livre de $\sim 60 \mathrm{~cm}$ ) necessário para a penetração do intervalo especificado. Com isso, um índice de resistência à penetração foi obtido. Os procedimentos realizados na abertura dos testemunhos consistiram em diferenciações faciológicas, amostragens de sedimento e amostragem de carapaças de moluscos (fósseis), identificação de estruturas sedimentares e biológicas e fotografias contínuas em alta resolução. As amostras de carapaças foram identificadas com uso de lupa binocular. Um analisador de partículas a laser $\mathrm{Horiba}^{\circledR}$ modelo LA-950 que utiliza a dispersão de Mie (difração a laser) foi empregado nas análises granulométricas e as análises morfoscópicas foram realizadas por meio de lupa estereoscópica binocular.

\subsubsection{Predição de ondas na Lagoa dos Quadros}

A ação hidrodinâmica produzida pelas ondas de gravidade na lagoa foi estimada através do modelo teórico de predição de ondas do Cor- po Engenheiros do Exército dos Estados Unidos (USACE) denominado Shore Protection Manual (USACE, 1984), atualizado na publicação Coastal Engineering Manual (USACE, 2006). A modelagem de ondas através do modelo teórico de predição de ondas do USACE utiliza as formulações para ondas de águas rasas de Hallermeier, 1980 (apud Hallermeier, 1981). Os dados gerados a partir do modelo foram: altura e período de onda e velocidade orbital das ondas em superfície e no fundo.

\section{Resultados e discussão}

\subsection{Características morfológicas}

A planície da margem NE da lagoa é composta por cerca de 20 cordões contínuos e semi-contínuos, dispostos em quatros subconjuntos (sets) separados por truncamentos (Fig. 2A). Esses truncamentos, caracterizados por mudanças na orientação dos cordões, podem evidenciar alterações energéticas dos agentes fluidodinâmicos, variações no suprimento sedimentar e variações do nível de base na história evolutiva do depósito (Curray et al., 1969; Tanner, 1995; Tamura, 2012). Em termos geomorfológicos essa planície pode ser considerada uma planície regressiva (strandplain) clássica (sensu Reinson, 1992).

É relevante ressaltar que a área de estudo é amplamente impactada devido às atividades agrícolas e agropecuárias. Tais práticas se iniciaram ainda nos anos 70 e, com isso, a morfologia original dos sistemas de cordões pode ter sofrido pequenas alterações. Como pode ser verificado em um dos perfis altimétricos (Fig. 3), os cordões são espaçados entre 5 a 50 m com amplitude (distância vertical entre a crista do cordão e sua cava) entre 0,30 a $1,50 \mathrm{~m}$ e altura média de 2,231 m em relação ao NRM. A altitude da atual linha de costa da lagoa é variável devido à variabilidade da precipitação pluviométrica, e no período do levantamento altimétrico ocupava uma altitude de cerca de $0,75 \mathrm{~m}$ em relação NRM.

Os 14 perfis altimétricos levantados, equidistantes entre si em cerca de $400 \mathrm{~m}$, demonstram que há uma tendência geral de diminuição das alturas dos cordões mais internos para os mais externos (mais próximos à margem da lagoa), ou seja, os cordões mais antigos possuem maior altitude. Esta tendência pode ser o resultado de um rebaixamento geral do NRM e consequentemente do nível de base da lagoa, a partir do Holoceno. É possível inferir, ainda, que a formação dos cordões ocorre após o desenvolvimento de um sistema de espo- 


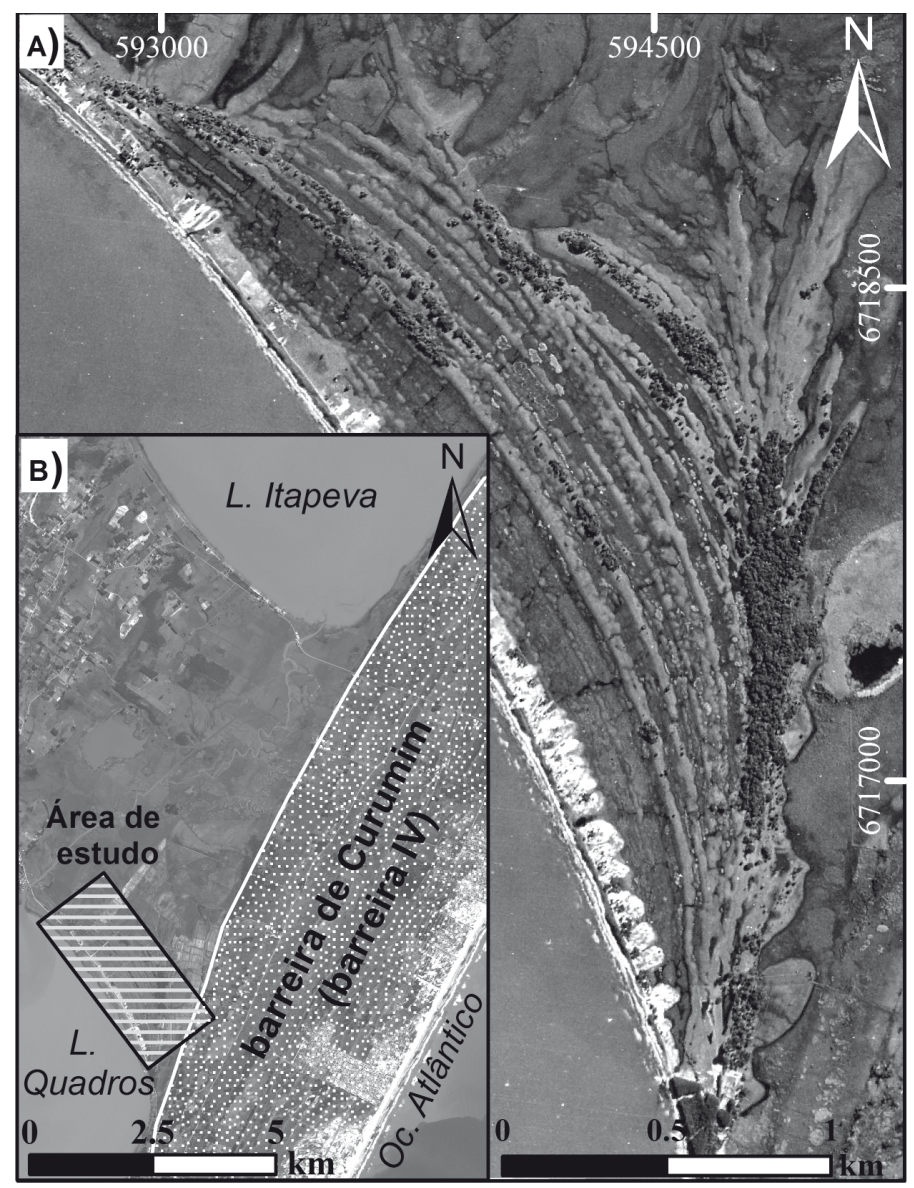

Figura 2. Fotografia aérea histórica de 1948: à época, a morfologia estava intacta (A) e imagem de satélite com a relação atual entre as lagoas dos Quadros e Itapeva e a barreira holocênica de Curumim (B) - barreira IV.

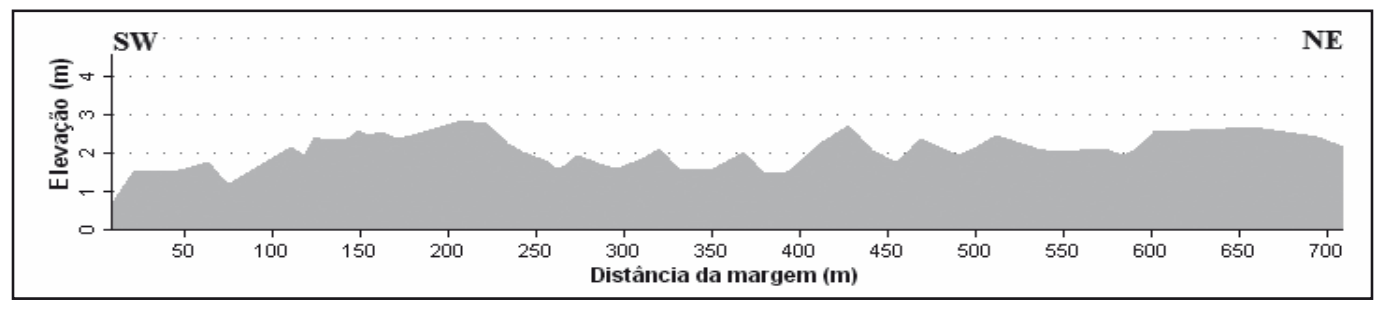

Figura 3. Seção transversal da altura dos cordões e cavas em relação ao nível relativo do mar (NRM) atual. Os depósitos eólicos podem ser notados entre 150 a 250 m de distância da margem lacustre (ver Fig. 4). Perfil 3 (localização na Fig. 1).

rões recurvados (observados mais internamente na planície), provavelmente quando as lagoas dos Quadros e de Itapeva tinham maiores dimensões e eram mais livremente conectadas, associadas a um NRM acima do atual (Fig. 2B).

A porção mais externa da planície exibe depósitos de leques de sobrelavagem em conjunto com depósitos arenosos de origem eólica que chegam a atingir até $2 \mathrm{~m}$ de altura (Fig. 4), como pode ser identificado no perfil altimétrico exemplificado (Fig. 3), e sua extensão litorânea acompanha a maior parte da margem planície. Esses depósitos são separados da atual linha de costa da lagoa por uma planície de inundação. Por definição, essa planície de inundação lacustre consiste numa área relativamente plana e sujeita a inundação periódica associada a um regime climático e hidrológico, onde normalmente se dá a deposição temporária de sedimento. Associados à atual margem NE da lagoa (planície de inundação) há vegetação formada predominantemente por juncais.

Em relação à análise da morfologia superficial, a grande variabilidade dos espaçamentos e amplitude, juntamente com os padrões de truncamentos, cordões contínuos e cordões sem continuidade, bem como a presença de deposição eólica, pressupõe-se que a construção da planície alternou entre mecanismos praiais (cordões de praia) e, outrora, mecanismos predominantemente eólicos (cordões de duna). A fotografia que mostra a presença de depósitos eólicos próximo da atual margem lacustre (Fig. 4) reforça que a planície deve ter se desenvolvido por meio da sucessiva justaposição de cordões de dunas frontais (cordões 
eólicos) e cordões de praia. Ou seja, caracterizando uma planície/barreira complexa (sensu McKee, 1979). Corrobora a essa classificação de barreira complexa a definição de Otvos (2012), na qual essa terminologia implica na existência de componentes eólicos e marinhos (praiais).

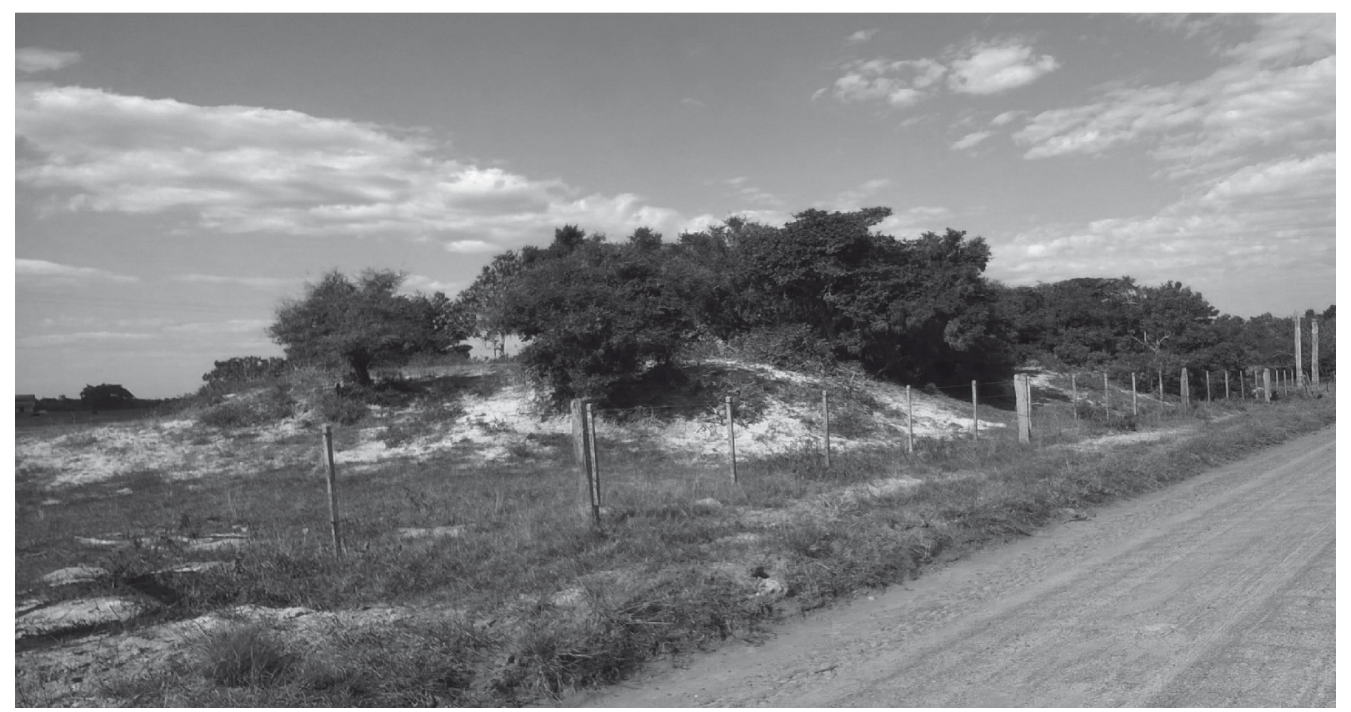

Figura 4. Fotografia dos depósitos eólicos próximo da margem NE da Lagoa dos Quadros.

Embora sejam mais comuns planícies de cordões de origem eólica com maior altura (e.g. Hesp, 1984; Mauz et al., 2013), resultados semelhantes aos obtidos neste trabalho foram encontrados por Forsyth et al. (2012), onde uma baixa amplitude foi verificada numa planície complexa, composta por cordões de dunas frontais e cordões de praia na Praia Wonga (Austrália). No setor sul da PCRS, a barreira do Cassino é formada pela justaposição de cordões de dunas frontais com baixa amplitude e espaçamento entre 20 a $50 \mathrm{~m}$, configurados em seis subconjuntos (Clerot, 2004; Dillenburg et al., 2009). Por se tratar de uma barreira em ambiente de mar aberto, a energia envolvida na gênese e as dimensões e espessuras dos depósitos arenosos da barreira de Cassino são substancialmente maiores em comparação com a Lagoa dos Quadros.

A interpretação da fotografia aérea de 1948 (Fig. 2A) mostra, ainda, rupturas relíquias dispostas irregularmente na maior parte dos cordões contemporâneos a esta data; portanto, há evidência de retrabalhamento eólico nas porções superiores de alguns cordões mais proeminentes.

Para Hesp et al. (2005), os espaçamentos variáveis e relativamente estreitos, juntamente com as orientações dos cordões da planície de cordões da margem nordeste da Lagoa dos Quadros, indicam que a planície é composta por cordões litorâneos regressivos com presença de dunas frontais. Contudo, é importante salientar que classificações mediante o emprego de imagens orbitais e fotografias aéreas apresentam incertezas. Muitas planícies de cordões podem ser classificadas erroneamente como formadas por cordões de dunas frontais ou cordões de praia, em razão da grande semelhança entre os dois tipos morfológicos quando visualizadas em produtos de sensoriamento remoto (Otvos, 2000; Hesp et al., 2005).

\subsection{Arquitetura deposicional}

O levantamento geofísico de alta resolução, que totalizou aproximadamente $2 \mathrm{~km}$ de registros de GPR, possibilitou identificar radarfácies correspondentes aos sistemas deposicionais característicos dos sistemas de cordões litorâneos regressivos. Dois trechos de GPR nas frequências de 400 e $80 \mathrm{MHz}$ foram selecionados e apresentados nas figuras 5 e 6, respectivamente. As características das radarfácies estão sintetizadas na tabela 1.

Padrões de refletores similares, principalmente nas fácies sotopostas aos cordões, foram descritos em radarfácies na barreira regressiva da Pinheira (SC), em estudos conduzidos por Barboza et al. (2009) e Dillenburg et al. (2011). 0 registro do capeamento eólico sobre depósitos de pós-praia e face da praia foi, também, individualizado com uso do GPR por Rocha et al. (2013), em sistemas de cordões pleistocênicos no complexo deltaico do Paraíba do Sul (RJ). Ainda na costa do Rio de Janeiro, radarfácies semelhantes foram descritas por Moulton et al. (2013), num estudo sobre a gênese e morfologia de dunas frontais. Cabe ressaltar trabalhos precursores de GPR associados à fácies eólicas, como Bristow et al. (2000a, 2000b).

Refletores de depósitos eólicos (dunas fron- 
tais) no topo, sucedidos por refletores de pós-praia (backshore), face da praia (beachface) e antepraia (shoreface) na base, foram amplamente descritos e interpretados na PCRS e no sul de Santa Catarina (e.g. Barboza et al., 2009, 2011b, 2013; Dillenburg et al., 2009, 2013; Biancini da Silva et al., 2010; Fracalossi et al., 2010; Manzolli, 2011; Lima, 2012; Dillenburg \& Barboza, 2014; Barboza \& Rosa, 2014).

As radarfácies B, C e D das figuras 5 e 6 correspondem a uma sequência regressiva (sensu Roy et al., 1994), com aproximadamente 3 a $4 \mathrm{~m}$ de espessura, na qual a progradação pode ser entendida genericamente como uma sucessão de antepraias desenvolvidas de NE para SW, sob depósitos de pós-praia/face de praia, sendo estes últimos recobertos, em alguns cordões de praia por depósitos eólicos (capeamento eólico) e justapostos por cordões com origem predominantemente eólica (antigas dunas frontais). Os cordões de praia podem ser relacionados à radarfácies $\mathrm{C}$, uma vez que cada cordão representa uma paleopraia, ou seja, uma face de praia relíquia (preservada pela regressão da linha de costa).

Refletores obliquo-tangenciais, com inclinação na ordem de 2,5ำ caracterizam a sucessão de antepraias, sobre a qual se desenvolveu os cordões litorâneos regressivos. 0 limite da ocorrência do capeamento eólico é demarcado por um forte refletor. Além da sucessão dos refletores obliquo-tangenciais, que caracterizam o pós-praia/face da praia e antepraia, foi verificado um registro de um depósito de preenchimento de canal (paleocanal), associado a um NRM mais baixo que o atual.

Em alguns pontos do registro, a fácies interpretadas como depósitos eólicos, geomorfologicamente sob a expressão de cordões de dunas frontais e capeamento eólico, possui espessura de até $1,5 \mathrm{~m}$ e sua extremidade inferior é marcada por um forte refletor. Esse refletor é característico do contato entre depósitos eólicos e depósitos do pós-praia em planícies de cordões (e.g. Bristow \& Pucillo, 2006; Tamura et al., 2008). As cavas, em geral, apresentam acumulação de sedimentos lamosos e matéria orgânica, os quais resultam num fraco sinal nas seções de GPR.

Entretanto, em virtude da relativa homogeneidade do tipo de sedimento que compõe os cordões regressivos da Lagoa do Quadros, e da ausência de contrastes importantes no sinal de GPR causados por laminações de minerais pesados e diferenças no tamanho de grão, por exemplo, o registro geofísico não apresentou o nível de detalhe esperado (limites claros dos pacotes eólicos e praiais, por exemplo). Contudo, a antena de $80 \mathrm{MHz}$ permitiu identificar um registro de alta qualidade de um depósito de preenchimento de canal (channel filling) (Fig. 6). Registros relativos aos paleocanais são comuns nos corpos lagunares e lacustres da PCRS, principalmente na Lagoa dos Patos (Weschenfelder et al., 2010, 2014) e estão relacionados a um nível de base mais abaixo que o atual.

Além dos levantamentos geofísicos, foram realizados quatro furos de sondagem rasos (Fig. $1 \mathrm{e}$ tab. 2). Com esses testemunhos foi possível recuperar amostras sedimentares com altitudes entre $-3,8$ e $+2,6 \mathrm{~m}$.

Dillenburg et al. (2011) interpretaram mudanças das fácies eólicas (cordão de dunas frontais) para as fácies praiais pelo grau de compactação oriundo de sondagens do tipo SPT (Standard Penetration Test) na barreira da Pinheira, no litoral catarinense. Os autores, na ocasião, utilizaram o modo de formação do depósito para explicar as diferenças no grau de compactação. Enquanto os depósitos eólicos são formados por fluxo e queda de grãos (possuem uma alta porosidade e baixa compactação), os depósitos de pós-praia e da face da praia são gerados pelos fluxos e refluxos associados ao espraiamento das ondas, processo que resulta em uma alta compactação do depósito.

As análises da resistência à penetração (compacidade relativa e grau de compactação) dos quatro furos de sondagens auxiliaram na diferenciação de fácies eólicas (dunas frontais e capeamento eólico) e praiais através do aumento da resistência de penetração do cano no pacote sedimentar. Apesar de não haver um nível de significância estatística entre as batidas e a profundidade atingida pelas sondagens $\left(r=0,20\right.$ e $\left.R^{2}=0,04\right)$, foi observado aumento progressivo da resistência à penetração conforme foram atingidas maiores profundidades. Resultados similares para a PCRS foram descritos por Travessas et al. (2005), em que depósitos eólicos foram moderadamente compactados enquanto os depósitos de margem lagunar foram de moderadamente a muito compactados e depósitos praiais oceânicos são altamente compactados.

No geral, quatro fácies sedimentares diferenciadas nos testemunhos, em concomitância com os registros geofísicos de GPR, compõem o arcabouço estratigráfico da planície de cordões litorâneos: depósitos de fundo lagunar (na base), depósitos de antepraia lacustre, depósitos de pós-praia/face de praia lacustre e depósitos eólicos (capeamento eólico) (Fig. 7 e tab. 1). A figura 7 compara as altitudes dos testemunhos de sondagens e a espessura das respectivas fácies (idades em radiocarbono estão marcadas no estrato datado). Em alguns pontos encontram-se, ainda, fácies relativas aos 


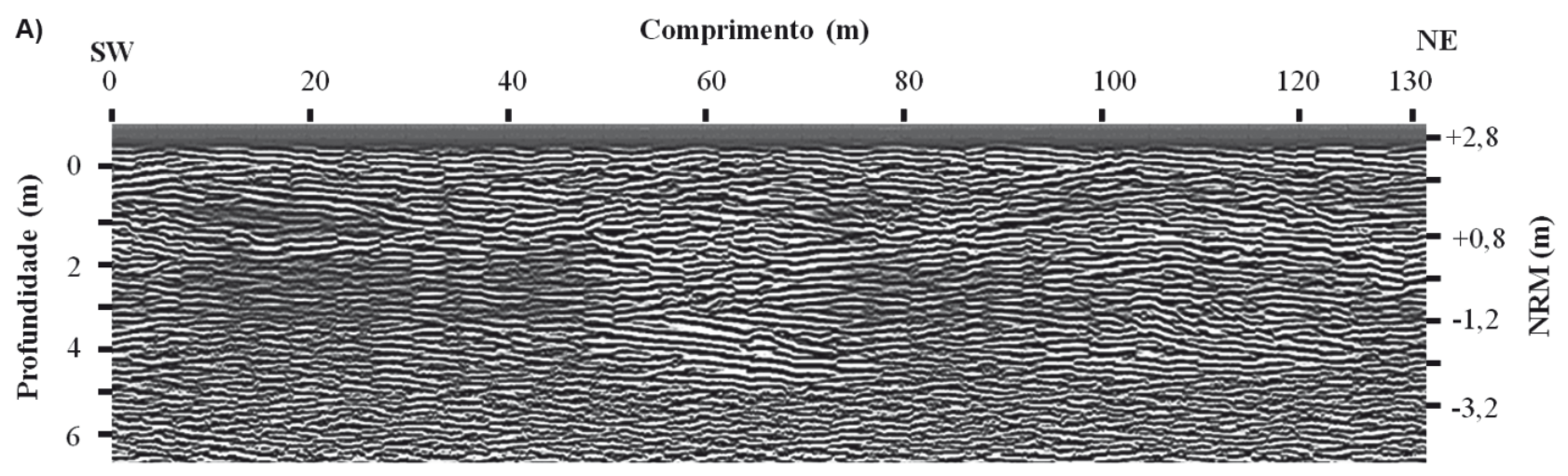

B)

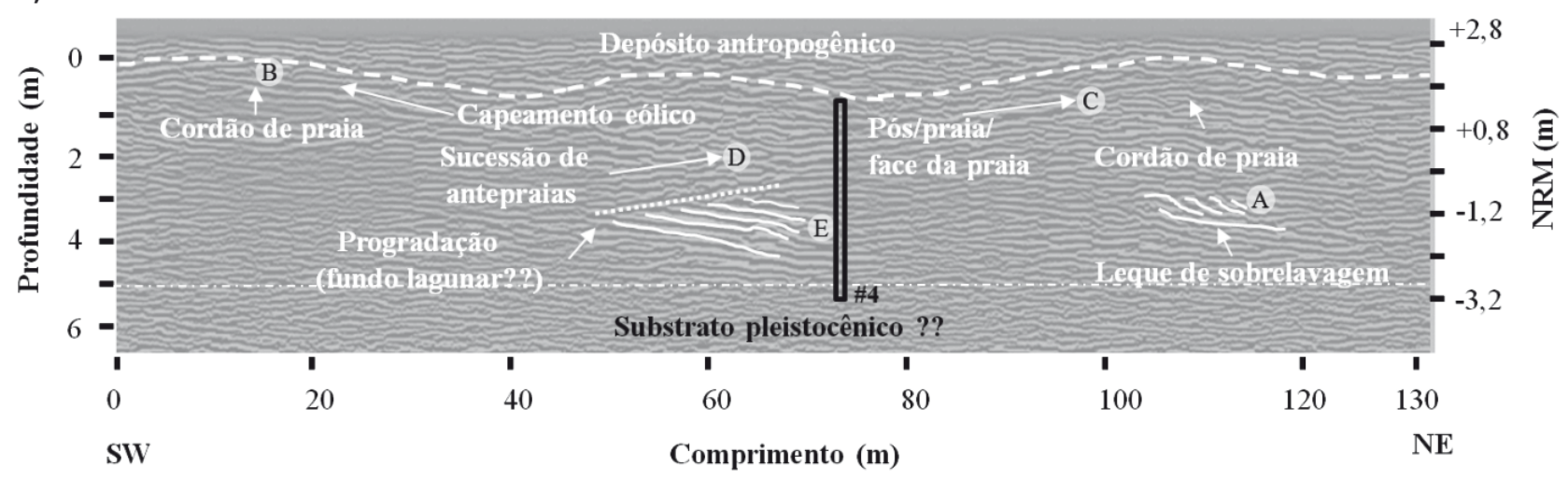

Figura 5. Seção de GPR com antena na frequência central de $400 \mathrm{MHz}$ processada (A) e interpretada (B). Sentido da margem da lagoa para SW. Descrição das radarfácies consta na tabela 1 e a localização das seções selecionadas na figura 1.
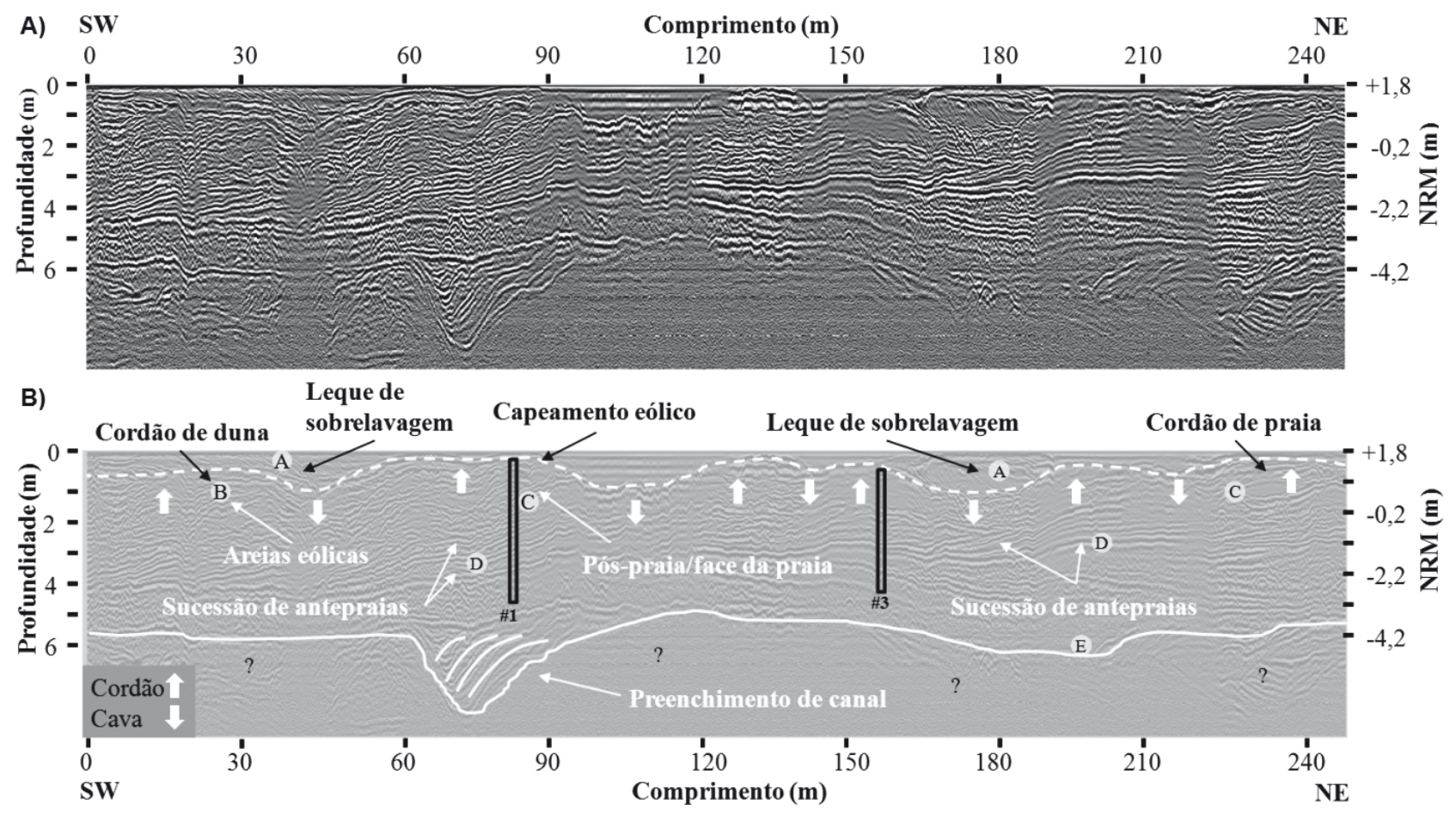

Figura 6. Seção de GPR com antena na frequência central de $80 \mathrm{MHz}$ (A) processada e (B) interpretada. Sentido da margem da lagoa para SW. Descrição das radarfácies consta na tabela 1 e a localização das seções selecionadas na figura 1. 
Tabela 1. Padrões dos refletores e interpretação ambiental.

Radarfácies
Refletores em alto ângulo, no
sentido contrário à margem da
lagoa.

depósitos de leque de sobrelavagem. Ou seja, cinco fácies sedimentares no total. Sumariamente, as características sedimentares encontradas nos depósitos remetem a sedimentos quartzosos policíclicos, similares às areias dos depósitos arenosos da barreira holocênica da PCRS.

As fácies superiores, que englobam os leques de sobrelavagem, o capeamento eólico e os cordões de dunas frontais apresentam o mesmo tipo de sedimento. Esses são compostos primordialmente por areia fina $(70-80 \%)$ a média $(20$ - 25\%), de coloração amarelada clara (rock color chart: 5 Y 7/6; 5Y8/4), bem a muito selecionada e muito pouco compactada. Outra característica importante é a grande presença de raízes. Análises morfoscópicas permitiram identificar que os grãos dessa fácies são, em sua maioria, sub-arredondados $(>65 \%)$ com textura superficial lisa e polida e boa esfericidade. As fácies do pós-praia/ face da praia lacustre são compostas basicamente por areias fina $( \pm 70 \%)$, média $( \pm 10 \%)$ e muito fina ( $\pm 15 \%$ ), cor acinzentada (rock color chart: 5 Y 5/2; $5 Y$ 4/1), bem compactada e apresenta laminações plano-paralelas e baixo ângulo de mergulho. Há ainda, nessa fácies, ocorrência de bioturbação caracterizadas por manchas irregulares de matéria orgânica.

Os depósitos caracterizados como antepraia lacustre (radarfácies D) são constituídos por areias fina ( $\pm 75 \%)$, média ( $\pm 15 \%$ ) e muito fina (20\%), de cor cinza clara esverdeada a cinza escura (rock color chart: 5 Y 2/1; 5YR 2/1), com presença de laminações de lama e matéria orgânica, moderadamente a muito compactada e relativa presença de fragmentos e carapaças de moluscos.

A fácies que representa o depósito de fundo lagunar, correlacionável à radarfácies $\mathrm{E}$, se caracteriza por uma maior presença de finos (lama) e, consequentemente, a uma maior quantidade de carapaças de moluscos. Há, também, laminações de areia fina a muito fina. A cor dessa unidade é cinza claro-esverdeado a cinza muito escuro (rock color chart: 5RY 2/1; 5Y 2/1). Na seção de 400 $\mathrm{MHz}$, a progradação dessa fácies relacionada ao furo de sondagem PLQUA 4, apresenta alta amplitude de sinal devido, basicamente, à grande presença de laminações com grande concentração de carapaças de moluscos.

A partir da coleta de carapaças da macrofauna, em diferentes níveis dos testemunhos, na fácies de antepraia lacustre e de fundo lagunar, foram identificadas dez espécies de moluscos, entre gastrópodes e bivalves, que têm preferência por ambiente marinho raso e mixohalino (Fig. 8). As carapaças estavam presentes apenas em dois testemunhos: no mais proximal (1) e no mais distal (4) da margem da lagoa (ver localização na Fig. 1), e nas fácies sotopostas à fácies eólica. 
As quatro datações por ${ }^{14} \mathrm{C}$ por espectrometria de massa com aceleradores (EMA), realizadas na Beta Analytic Inc., foram calibradas para o hemisfério sul conforme Reimer et al. (2013) (Tab.3). Uma vez que as conchas datadas não estavam em posição de vida e apresentavam leves sinais de retrabalhamento, as idades obtidas devem ser consideradas como as idades máximas das camadas sedimentares de ocorrência das carapaças.

Há um consenso entre a maior parte comunidade científica a respeito do comportamento do nível do mar entre os estágios finais do Pleistoceno e início do Holoceno para a costa brasileira. Pes- quisas conduzidas no sul do Estado de Santa Catarina mostram que o NRM entre 6 - 5 ka alcançou de 2 a $3 \mathrm{~m}$ acima do atual, seguido por uma queda até o presente nível (Angulo \& Lessa, 1997; Angulo et al. 1999 ; 2006). Na PCRS, mais especificamente no litoral médio, Barboza \& Tomazelli (2003) chegaram a mesma magnitude, em interpretações relativas à formação de um terraço lagunar holocênico (6 - $5 \mathrm{ka}$ ) na margem leste da Lagoa dos Patos.

Estudos sobre a matéria orgânica particulada dos sedimentos em furos de sondagens na Lagoa dos Quadros, realizados por Meyer et al. (2005; 2006), demonstram uma grande influência mari-

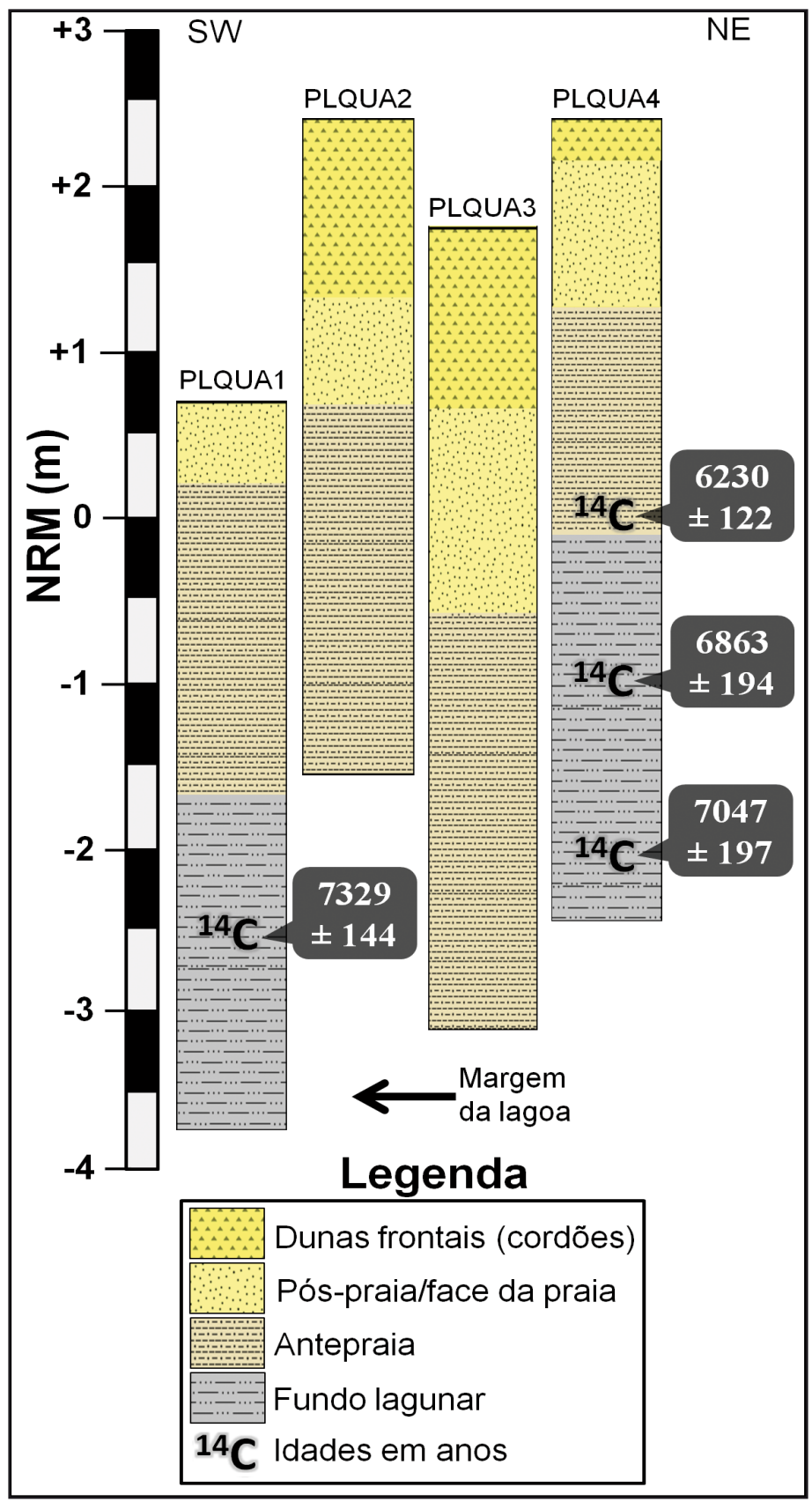

Figura 7. Seção esquemática sem escala horizontal dos perfis colunares (sondagens) da sequência progradacional da planície de cordões. Fácies relativas aos leques de sobrelavagem estão ausentes nos testemunhos. PLQUA1 está situado na linha de costa da lagoa. (Localização das sondagens na Fig. 1). 
nha entre 6,7 e 4,8 ka. Os autores denominam esse intervalo de tempo como Última Transgressão Marinha Lagunar, na qual houve uma grande influência marinha devido à alta concentração de um tipo comum de palinofácies (cistos de dinoflagelados e palinoforaminíferos). Dentro desse mesmo intervalo de tempo, as carapaças dos moluscos identificados nos testemunhos PLQUA também evidenciam uma franca influência marinha/mixohalina, provavelmente quando as lagoas de Itapeva e dos Quadros ainda estavam conectadas e possuíam ligações com o oceano.

As idades da sondagem PLQUA 4: $7.047 \pm 197$, $6.863 \pm 194$ e $6.230 \pm 122$ anos, com intervalos entre si de cerca de $1 \mathrm{~m}$, indicam uma taxa relativamente alta de sedimentação $\left(5,4\right.$ a $\left.1,4 \mathrm{~mm} \cdot \mathrm{ano}^{-1}\right)$. Embora a maioria das taxas de sedimentação nos corpos lagunares e lacustres da PCRS tenha sido calculada principalmente pela técnica de ${ }^{210} \mathrm{~Pb}$, ou seja, sedimentação curto período (e.g. Martins et al., 1989; Medeanic \& Dillenburg. 2005; Ivanoff, 2013), o estudo de Toldo Jr. et al. (2000) na Lagoa dos Patos, baseado em correlação estratigráfica e datações por radiocarbono, sugere uma sedimentação holocênica na ordem de $0,75 \mathrm{~mm} \cdot \mathrm{ano}^{-1}$. A sedimentação holocênica na Lagoa dos Quadros foi, muito provavelmente, superior à taxa da Lagoa dos Patos por alguns fatores, tais como: presença da Serra Geral ocasionando drenagens para seu interior (e.g. Rio Maquiné) e assoreamento devido a depósitos eólicos transgressivos da barreira holocênica adentrando nessa lagoa (Fig. 9).

0 intervalo de tempo entre a idade mais antiga e a mais nova corresponde a uma fase de agradação da fácies de fundo lagunar, induzida pelo estágio final de elevação holocênica do NRM, cujo clímax foi alcançado há cerca de 6 - 5 ka. Neste mesmo intervalo de tempo, a barreira holocênica, na região de Curumim, igualmente desenvolvia sua fase de agradação acompanhada por um início da progradação (Dillenburg et al., 2006, 2009).

Na PCRS, datações com idades similares em altitudes concomitantes, em lagunas e lagoas foram obtidas por Dillenburg (1994) e Travessas et al. (2005), por exemplo. A partir da datação das fácies sotopostas aos cordões, é possível supor que a formação e o desenvolvimento dos cordões regressivos ocorreram após o clímax do NRM do Holoceno.

\subsection{Aspectos fluidodinâmicos e mecanismos de cons- trução de cordões}

A remobilização e transporte de partículas sedimentares, por ondas, junto ao fundo de um corpo de água são determinados pela velocidade orbital, que por sua vez depende da profundidade, tamanho do grão e da altura e período de onda. Segundo Hallermeier (1980, apud Hallermeier, 1981) para sedimentos não coesivos com um tamanho de grão entre 63 um e 2 mm (fração areia), a velocidade orbital junto ao fundo para que haja efetividade na remobilização e transporte de areia é de $0,13 \mathrm{~m} \cdot \mathrm{s}^{-1}$.

Para a PCRS, Dillenburg et al. (1992) e Tabajara \& Dillenburg (1997) utilizaram dados oriundos do modelo teórico de predição de ondas do USACE para explicar a composição mecânica e distribuição dos sedimentos superficiais de fundo da laguna de Tramandaí. Recentemente, Ivanoff et al. (2014) encontraram resultados satisfatórios com o uso dessa metodologia na Lagoa de Itapeva.

Os valores de direção, frequência e intensida-

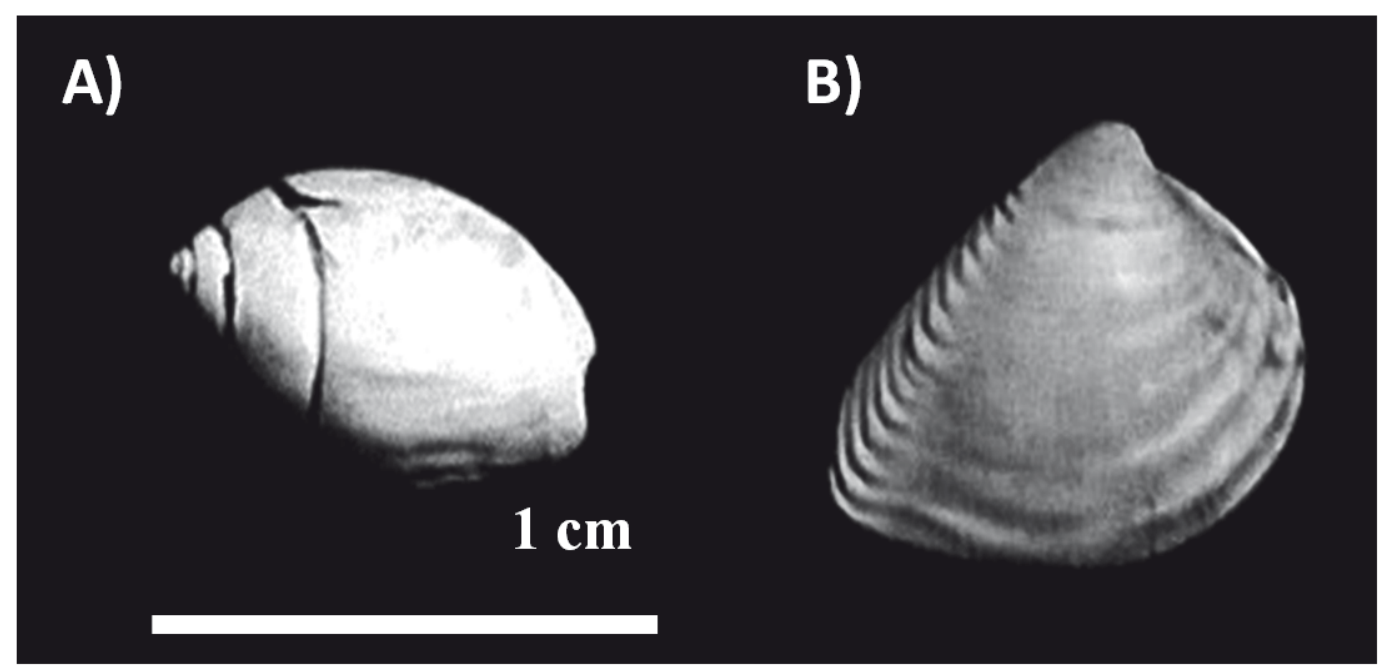

Figura 8. Fotografias de duas espécies de moluscos de um total de dez identificadas no substrato lagunar na qual a planície de cordões se desenvolveu. A) Olivella tehuelcha; B) Anomalocardia brasiliana. 
Tabela 2. Coordenadas e metadados dos furos de sondagens (localização na fig. 1; UTM22J: SIRGAS2000).

\begin{tabular}{cccccc}
\hline Testemunho & Lat. & Long. & Comprimento (m) & Altitude (m) - NRM & Técnica \\
\hline PLQUA 1 & 6716371 & 594287 & 4,49 & 0,76 & Vibro coring \\
PLQUA 2 & 6716444 & 594523 & 3,87 & 2,63 & Percussão \\
PLQUA 3 & 6716447 & 594604 & 4,75 & 1,53 & Percussão \\
PLQUA 4 & 6718717 & 593901 & 4,70 & 2,26 & Percussão \\
\hline
\end{tabular}

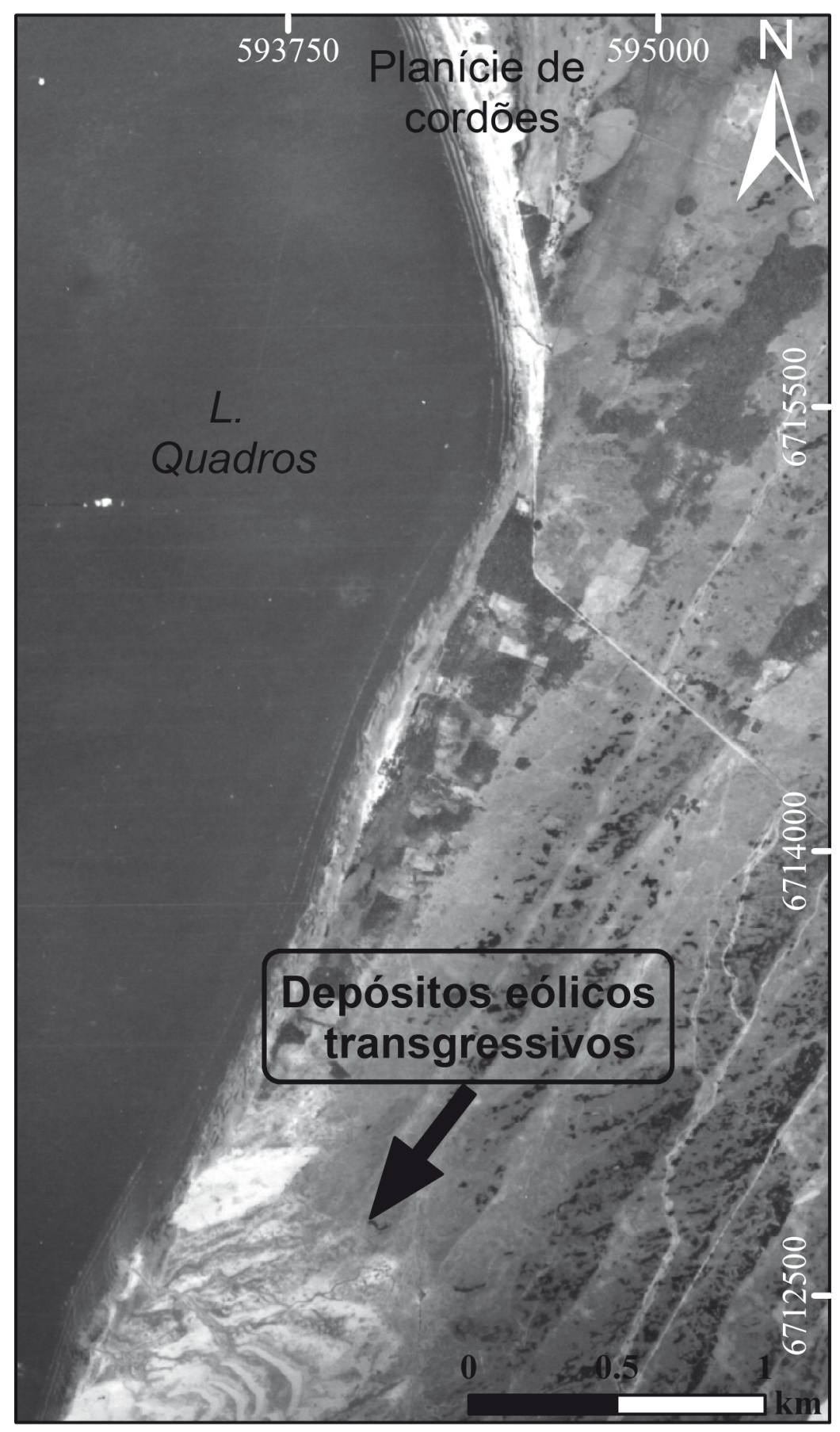

Figura 9. Fotografia aérea de 1964 mostrando depósitos eólicos de natureza transgressiva com migração em sentido à Lagoa dos Quadros. 
Tabela 3. Análises geocronológicas por EMA ${ }^{14} \mathrm{C}$.

\begin{tabular}{cccccc}
\hline Testemunhos & № Beta & Prof. (NRM) & Idade convencional (anos) & Idade calibrada (anos) & Material datado \\
\hline PLQUA 1 & 382537 & $-2,5$ & $6800 \pm 30$ & $7329 \pm 144$ & Nucula semiornata \\
PLQUA 4 & 382540 & 0 & $5810 \pm 30$ & $6230 \pm 122$ & Erodona mactroides \\
PLQUA 4 & 382539 & $-1,0$ & $6390 \pm 30$ & $6863 \pm 194$ & Heleobia australis, Turbonilla sp. \\
PLQUA 4 & 382538 & $-2,0$ & $6530 \pm 30$ & $7047 \pm 197$ & $\begin{array}{c}\text { Anomalocardia brasiliana, Olivella } \\
\text { tehuelcha }\end{array}$ \\
\hline
\end{tabular}

de dos ventos aplicados ao modelo foram obtidos de Cardoso et al. (2003) (Fig. 10), da mesma forma como realizado por Ivanoff et al. (2014) para a Lagoa de Itapeva. Adquiridos por meio de uma estação móvel e com uma curta série temporal, os dados de Cardoso et al. (2003) são os mais correlacionáveis aos dados da área de estudo e, consequentemente, representam os padrões de ventos com maior fidelidade em comparação aos dados de ventos de estações com maior série de dados, porém, mais distantes. Sendo assim, foram gerados os seguintes dados a partir do modelo do USACE: altura e período de onda e velocidade orbital das ondas em superfície e no fundo (Tab. 4).

Conforme demonstrado pelos dados da tabela 4 , ventos do quadrante SW-SSW com velocidades a partir de $8 \mathrm{~m} \cdot \mathrm{s}^{-1}$ já são capazes de remobilizar sedimento arenoso na profundidade média da lagoa, que corresponde a aproximadamente $3 \mathrm{~m}$. Esta profundidade apresenta concordância com o limite de deposição de sedimentos grossos (areia) e finos (lama) identificados nos mapas de distribuição de sedimentos de fundo e batimétrico por Cwik (1999).

Em virtude da reduzida profundidade da porção NE da Lagoa dos Quadros, inferior a 1,5 m, conforme demonstrado por Cwik (1999), é possível inferir que ventos de SW-SSW geram ondas capazes de transportar sedimento na fração areia em direção à margem NE da lagoa, onde se desenvolveu a planície de cordões litorâneos regressivos. Tais ondas são hábeis, ainda, em acoplar e soldar barras submarinas arenosas (longshore bar) na face da praia, um dos modos de formação de cordões de praia conforme Curray et al. (1969) e Komar (1976).

É possível verificar ainda, conforme os dados de Cardoso et al. (2003), que há períodos em que os ventos com componentes do quadrante SW-SSW apresentam uma maior participação no regime de ventos. Estes mesmos ventos, responsáveis pela geração de ondas na lagoa, com importante incidência na sua margem NE, produzem provavelmente o retrabalhamento eólico sobre os cordões e a consequente formação de capeamento eólico e rupturas de deflação (processo genérico ao descrito por Hesp, 1984 e 1999). 0 sistema de esporões recurvados (Fig. 2A), precedentes ao desenvolvimentos da planície de cordões, possivelmente teve sua gênese a partir de correntes lacustres de sentido $\mathrm{S}-\mathrm{N}$, e sugere que ventos do quadrante sul também possam vir a atuar com força e constância consideráveis.

Para que haja efetivamente transporte eólico, principalmente por saltação, a velocidade do vento deve ultrapassar o que Bagnold (1941) define como limite do fluido (fluid threshold). A velocidade necessária para atingir esse limiar depende em grande parte do tamanho do grão, muito embora existam diversas outras variáveis envolvidas no transporte eólico, como umidade do sedimento, rugosidade do terreno, temperatura, dentre outras (Hesp, 1999). Basicamente, dois fatores são essenciais para formação de depósitos eólicos: suprimento de areia e ventos persistentes e fortes o suficiente para movimentá-la (McKee, 1979). Ambos fatores são encontrados na Lagoa dos Quadros, em certas épocas do ano, em sua margem NE.

Além de ventos e ondas capazes de remobilizar, erodir e transportar areia, outro fator deve ser considerado: a alteração cíclica no volume d'água na lagoa. Variações no nível d'água de uma lagoa ocorrem em diversas escalas de tempo, desde variações muito rápidas, medidas em segundos até variações de centenas de anos e podem potencializar a atuação de ondas, formação de barras arenosas e processos de sobrelavagem (overwash), produzindo depósitos de leques de sobrelavagem (washover fans). Tais flutuações resultam principalmente do balanço entre processos meteorológicos e hidrológicos, dentre os quais é importante salientar a precipitação e evaporação (Hofmann et al., 2008).

Cwik (1999) ao analisar dados hidrometeorológicos nas imediações da lagoa entre 1984 a 1995 encontrou uma variação no volume da lagoa em conivência com dados pluviométricos para o mesmo período (Fig. 11A-B). A variação resultante do nível de inundação foi da ordem de $50 \mathrm{~cm}$, em média. Assume-se, então, que existe certa sazona- 
lidade em termos da variação no volume d'água na lagoa, e consequentemente no maior ou menor al- cance do espraiamento da onda, de acordo com a época do ano.
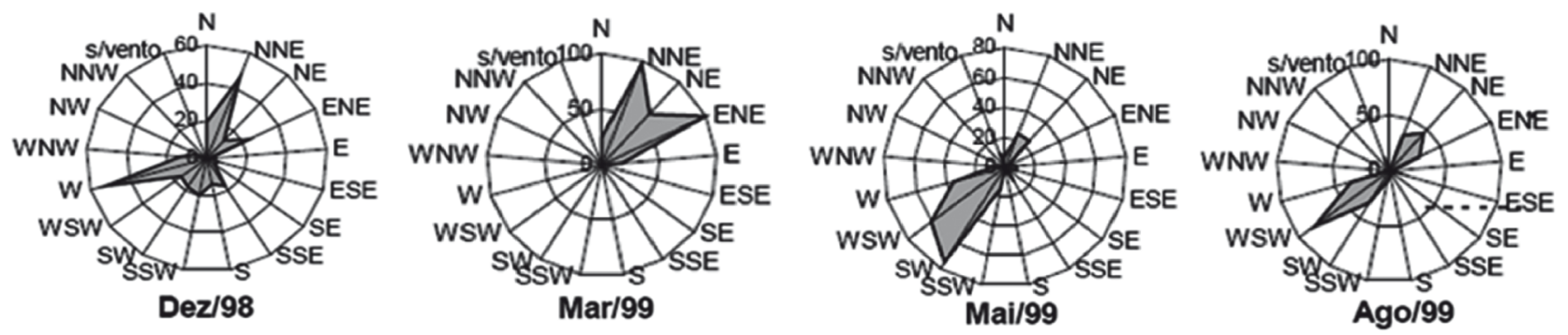

Figura 10. Frequência percentual (\%) da distribuição da direção dos ventos no extremo sul da Lagoa de Itapeva $(\sim 10 \mathrm{~km}$ ao N da Lagoa dos Quadros, ver fig. 2A) (Modificado de Cardoso et al., 2003).

Tabela 4. Parâmetros de ondas para a Lagoa dos Quadros gerado a partir da velocidade e frequência dos ventos.

\begin{tabular}{ccccccccc}
\hline & & Vento & & Pista & \multicolumn{2}{c}{ Ondas } & \multicolumn{2}{c}{ Velocidade Orbital (m·s $\mathbf{s}^{-1}$ ) } \\
\hline Estação & Direção & Frequência $\%$ & Velocidade $(\mathrm{m} / \mathrm{s})$ & $\mathrm{km}$ & Altura $(\mathrm{m})$ & Período (s) & Superfície & Fundo (3 m) \\
\hline Sul & N & 16,8 & 2,0 & 14,5 & 0,1 & 1,3 & 0,25 & 0 \\
Sul & N & 16,8 & 8,0 & 14,5 & 0,4 & 2,4 & 0,55 & 0,13 \\
Sul & N & 16,8 & 16,0 & 14,5 & 0,7 & 3,1 & 0,74 & 0,34 \\
Sul & NNE & 11 & 2,0 & 12,5 & 0,1 & 1,2 & 0,27 & 0 \\
Sul & NNE & 11 & 8,0 & 12,5 & 0,5 & 2,3 & 0,73 & 0,14 \\
Sul & NNE & 11 & 16,0 & 12,5 & 0,6 & 3,0 & 0,65 & 0,28 \\
Sul & NE & 12,7 & 2,0 & 12 & 0,1 & 1,2 & 0,27 & 0 \\
Sul & NE & 12,7 & 8,0 & 12 & 0,4 & 2,3 & 0,58 & 0,11 \\
Sul & NE & 12,7 & 16,0 & 12 & 0,6 & 2,9 & 0,68 & 0,27 \\
Sul & ENE & 9,2 & 2,0 & 12,4 & 0,1 & 1,2 & 0,27 & 0 \\
Sul & ENE & 9,2 & 8,0 & 12,4 & 0,4 & 2,3 & 0,58 & 0,11 \\
Sul & ENE & 9,2 & 16,0 & 12,4 & 0,6 & 3,0 & 0,65 & 0,28 \\
Sul & E & 3,9 & 2,0 & 12 & 0,1 & 1,2 & 0,27 & 0 \\
Sul & E & 3,9 & 8,0 & 12 & 0,4 & 2,3 & 0,58 & 0,11 \\
Sul & E & 3,9 & 16,0 & 12 & 0,6 & 2,9 & 0,68 & 0,27 \\
Norte & S & 6,6 & 2,0 & 14,5 & 0,1 & 1,3 & 0,25 & 0 \\
Norte & S & 6,6 & 8,0 & 14,5 & 0,4 & 2,4 & 0,55 & 0,13 \\
Norte & S & 6,6 & 16,0 & 14,5 & 0,7 & 3,1 & 0,74 & 0,34 \\
Norte & SSW & 10,6 & 2,0 & 12,5 & 0,1 & 1,2 & 0,27 & 0 \\
Norte & SSW & 10,6 & 8,0 & 12,5 & 0,5 & 2,3 & 0,73 & 0,14 \\
Norte & SSW & 10,6 & 16,0 & 12,5 & 0,6 & 3,0 & 0,65 & 0,28 \\
Norte & SW & 11,1 & 2,0 & 12 & 0,1 & 1,2 & 0,27 & 0,11 \\
Norte & SW & 11,1 & 8,0 & 12 & 0,4 & 2,3 & 0,58 & 0,68 \\
Norte & SW & 11,1 & 16,0 & 12 & 0,6 & 2,9 & 0,68 & 0,27 \\
\hline & & & & & & &
\end{tabular}

Na margem NE da lagoa, a variação cíclica do nível faz com que a planície de inundação lacustre chegue a alcançar cerca de 90 m de extensão, magnitude esta alcançada em meses com intensa pluviosidade (Fig.12A-B). Em alguns pontos dessa margem, ocorrem depósitos arenosos de sobrelavagem atuais sobre a planície de inundação lacustre, associados a ventos e ondas provenientes de SW e SSW (Fig. 13A-B). Os depósitos de leques de sobrelavagem são tratados aqui como areia acumulada na planície de inundação lacustre, em decorrência de ondas de tempestades e nível d'água elevado, e podem ser verificados nas seções de GPR (radarfácies A).
A literatura sobre processos e depósitos de sobrelavagem é basicamente restrita a costas oceânicas, porém, analogias podem ser feitas para corpos lagunares e lacustres. Ruz \& Meuer-Ferec (2004) realizaram estudos sobre a influência de níveis d'água elevados no transporte eólico e comprovaram o potencial erosivo do efeito combinado de tempestades e níveis d'água elevados em depósitos eólicos. Comumente, os processos de sobrelavagem acabam por erodir as dunas frontais, dependendo de sua magnitude (Psuty, 1992). Entretanto, segundo Ritchie \& Penland (1988), a areia estocada no leque de sobrelavagem, principalmente na fração areia fina, pode ser facilmente 


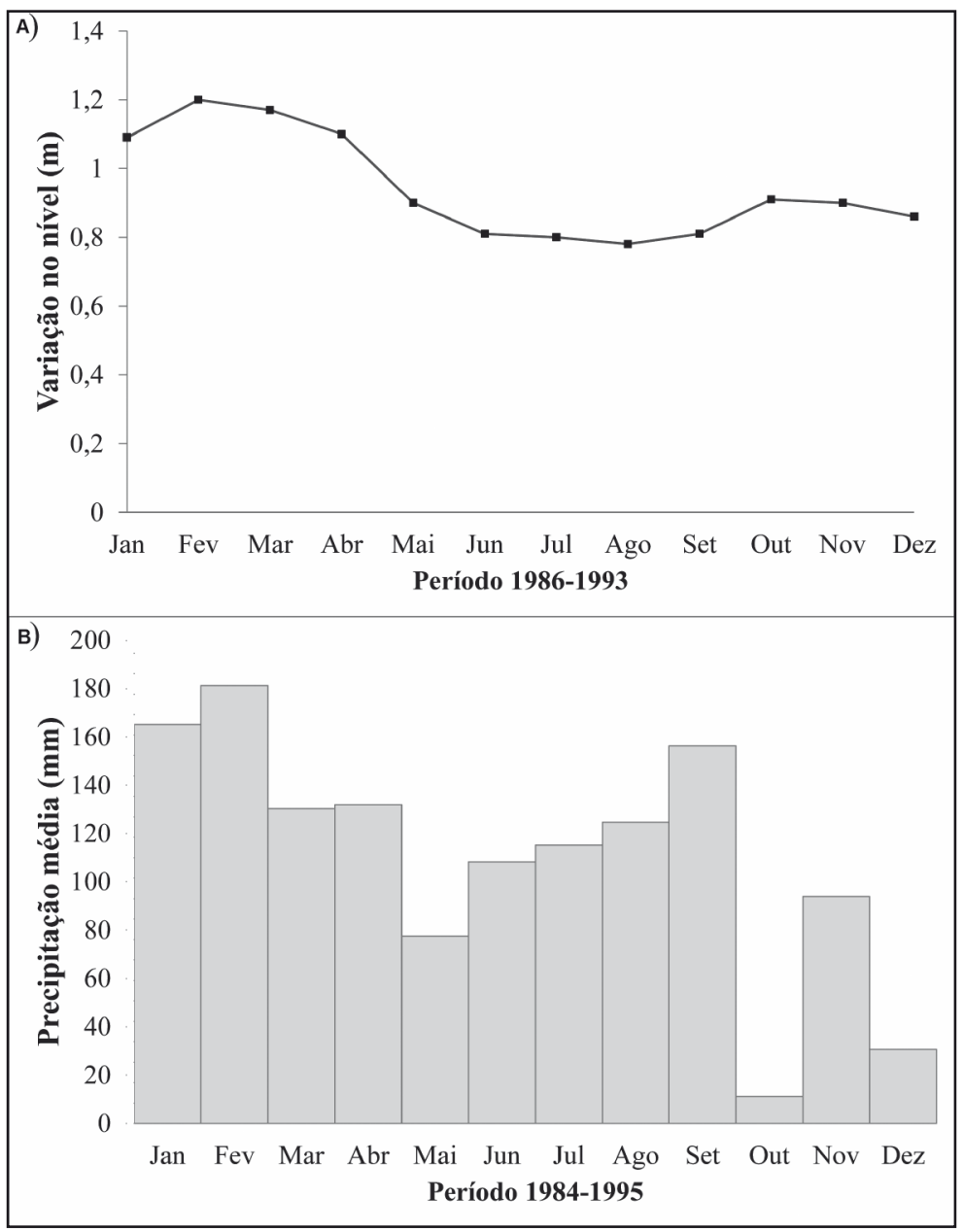

Figura 11. Variação no nível (volume) d'água na lagoa entre os anos 1986-1993 (A) e precipitação média mensal entre $1984-$ 1995 (B) (Modificado de Cwik, 1999).

retrabalhada por processos eólicos em uma grande variedade de dunas, dentre as quais a duna frontal que é rapidamente vegetada.

Leatherman \& Zaremba (1987), em estudos sobre processos de sobrelavagem na costa nordeste dos EUA, constataram uma grande relação entre depósitos de leques de sobrelavagem, processos eólicos e períodos com ausência de tempestades, na qual cerca de metade do volume sedimentar estocado no leque de sobrelavagem foi retrabalhado pelo vento, retornando a face da praia, enquanto o restante permaneceu acumulado sob a forma de dunas.

Na PCRS, Barboza (1999) demonstrou a formação de depósitos de dunas transgressivas, com pequenas elevações, associadas ao retrabalhamento de leques de sobrelavagem, pelo vento, na Lagoa dos Patos.

A eficiência da deflação eólica sobre leques de sobrelavagem depende do efeito combinado de três processos principais: frequência de ventos fortes, precipitação mensal e períodos sem precipitação (Kochel \& Wampfler, 1989). Ou seja, os ventos de SW-SSW predominantes em maio são mais efe- tivos na margem NE da lagoa, pois atuam durante períodos relativamente secos em comparação com outros períodos, e assim há menor resistência do sedimento para ser transportado.

Conforme Sanderson et al. (1998), dunas frontais, e posteriormente cordões de dunas frontais, podem se desenvolver em praias oceânicas a partir da formação de leques de sobrelavagem no pós praia durante condições de tempestades. Um processo análogo é observado na Lagoa dos Quadros, porém com as variáveis ambientais como ondas e correntes com menores magnitudes.

As imagens das figuras 14A, B e C esboçam o comportamento da margem lacustre através das fotografias aéreas históricas dos anos de 1948 e 1964, e da imagem do satélite SPOT-5 de 2005. É possível inferir uma variação regressiva na linha de costa da lagoa. Na figura 14B, de 1964, nota-se um grande estoque de areia, na forma de dunas frontais paralelas. À época, ventos do quadrante SW-SSW e períodos de baixa umidade encontrados na área de estudo, principalmente entre 1940 a 1970 (Hesp et al. 2007; Martinho et al., 2008), associados à disponibilidade de areia fina e a vege- 
tação no pós-praia da margem lacustre, sugerem períodos de intensa atividade e deposição eólica no pós-praia, permitindo uma acresção vertical nos cordões de praia e desenvolvendo cordões de dunas frontais. Embora ventos de NE sejam dominantes na maior parte do ano, a orientação da linha de costa da lagoa permite o desenvolvimento de dunas frontais a partir de ventos SW e SSW.

Segundo Bracco et al. (2005) e del Puerto et al. (2006), a formação dos sistemas de cordões lagunares na Laguna de Castillos (Uruguai) foi favorecida por variações climáticas globais, após 4,5 ka. Na ocasião, períodos climáticos mais secos foram responsáveis por uma maior contribuição de sedimentos arenosos para a laguna pela ação eólica, através do retrabalhamento do sistema de dunas de Valizas - Cabo Polônio. Num processo análogo, como pode ser visualizado na figura 9 ,
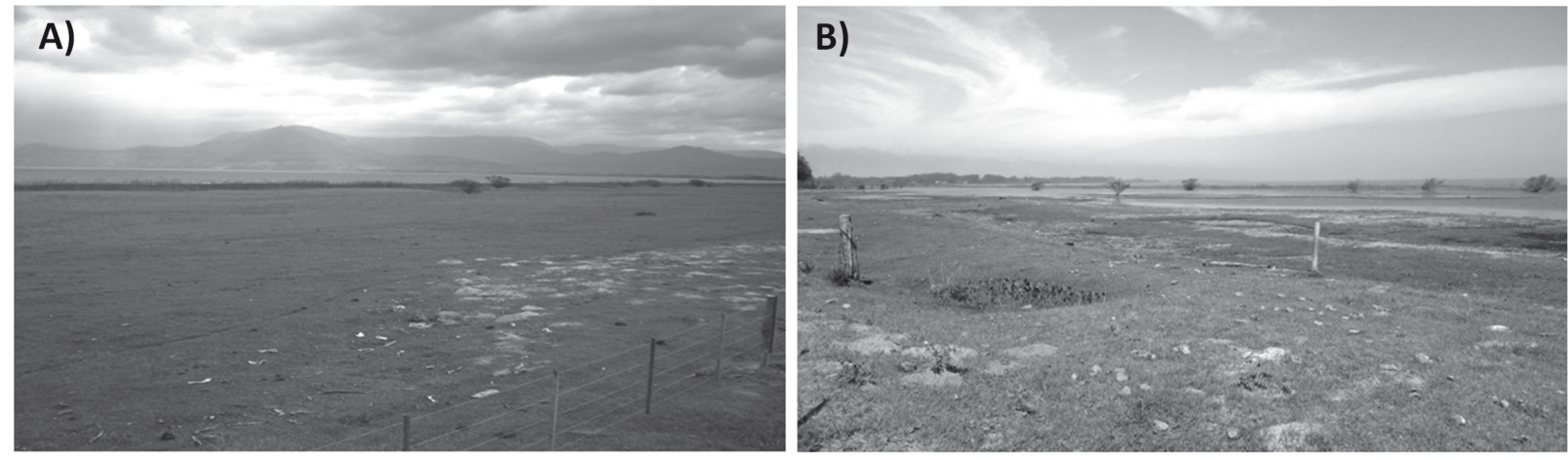

Figura 12. Comparação de uma foto da margem NE da lagoa em junho de 2013 (A) em relação a uma foto após um período de intensa pluviosidade, em outubro de 2013 (B); para referência do nível (extensão da linha de costa), utilizar as árvores ao fundo; é possível notar uma diferença de nível relacionada à planície de inundação lagunar mediante a comparação das duas fotos.
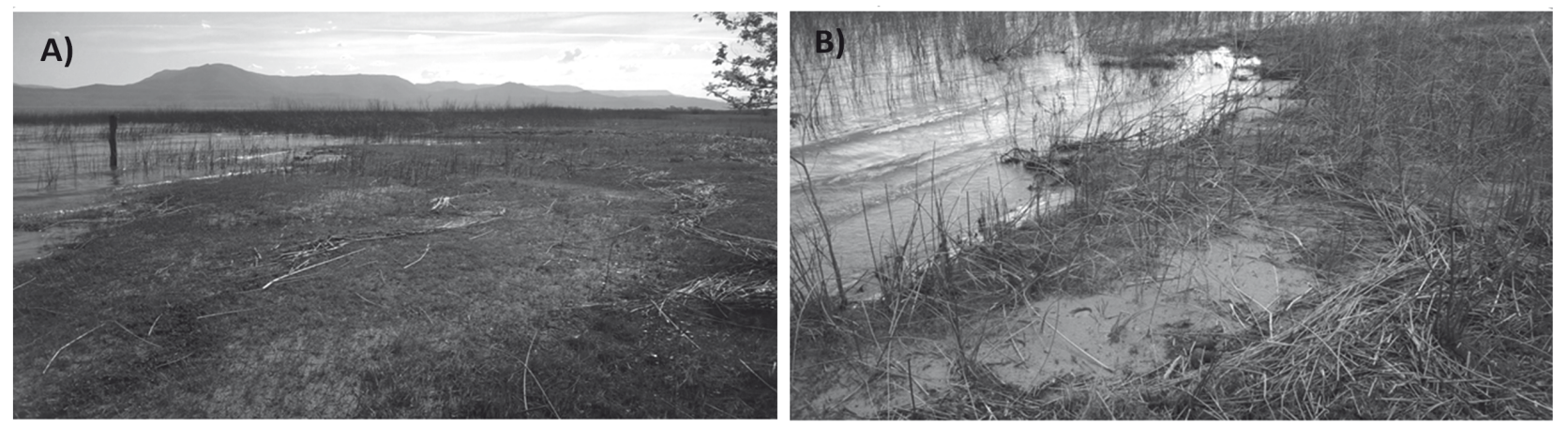

Figura 13. Registro de um leque de sobrelavagem na planície de inundação lacustre (A e B); fotos obtidas após a passagem de um sistema frontal (frente fria) no mês de agosto de 2014.
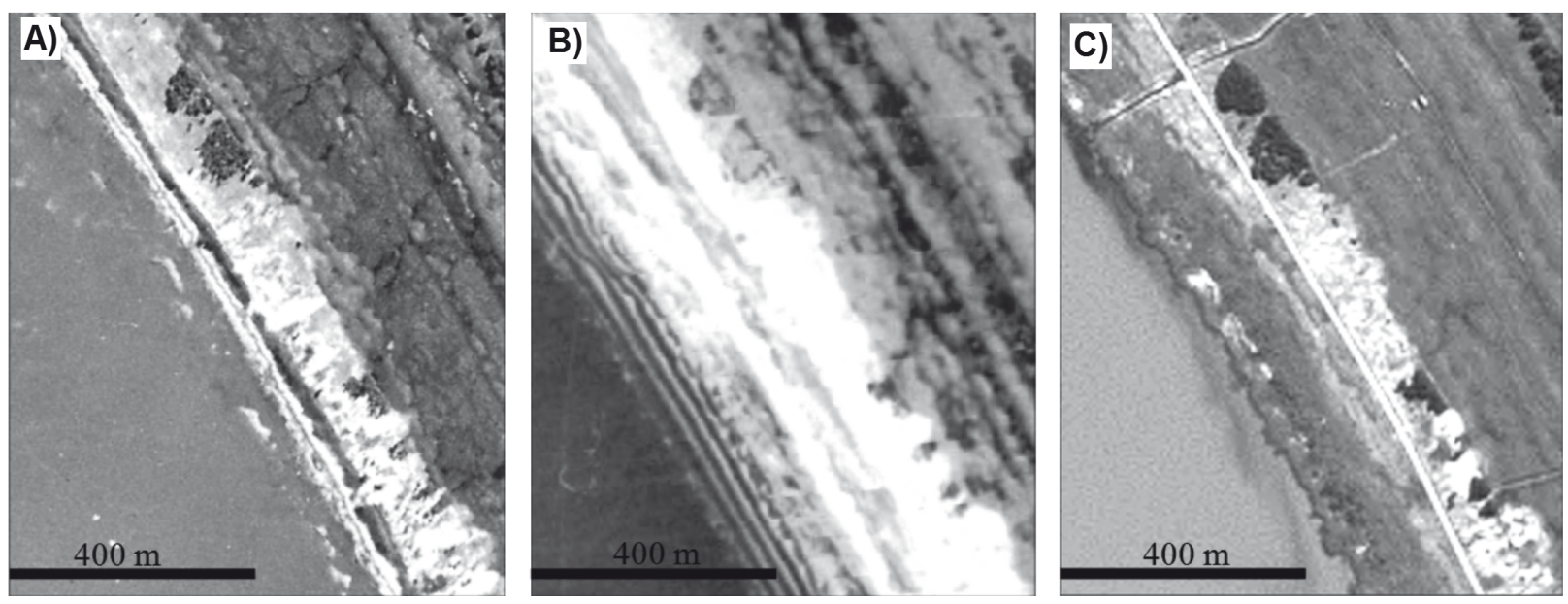

Figura 14. Comparação de um mesmo ponto da margem NE da lagoa entre 1948 (A), 1964 (B) e 2005 (C). Ver localização (retângulo) na figura 1 (os dois bosques na parte superior podem servir de referência). 
as fases de construção de campos de dunas transgressivos, nos estágios de agradação da barreira de Curumim (Hesp et al., 2005, 2007; Martinho et al., 2008), ocorrida entre 7,1 e 5,5 ka, podem ter contribuído com o transporte de areias para o interior da lagoa, pelo assoreamento por depósitos eólicos transgressivos, e assim proporcionado sedimentos para a construção da planície de cordões.

\section{Conclusões}

A planície de cordões litorâneos da Lagoa dos Quadros apresenta quatro subconjuntos de cordões separados por truncamentos (mudanças de orientação). Tais truncamentos marcam alterações no regime hidrodinâmico e/ou suprimento sedimentar. Um total de 20 cordões foi identificado, apresentando um espaçamento médio entre 5 a 50 m com amplitude entre 0,30 a $1,50 \mathrm{~m}$.

Aspectos geomorfológicos e dados de subsuperfície permitiram identificar cinco fácies sedimentares e o seu padrão de empilhamento na área de estudo. A sucessão vertical de fácies é composta por lama de fundo lagunar sobre a qual se desenvolveu uma sequência regressiva, composta por cordões litorâneos do tipo duna frontal e cordões de praia com um ocasional capeamento eólico.

A fácies basal de fundo lagunar registra a fase de agradação e progradação da fácies de fundo lagunar do sistema lacustre, ocorrida entre $7047 \pm$ 197 e $6230 \pm 122$ anos. A simulação de ondas geradas pelos ventos locais provenientes de $S$ e SW indicou que na atual condição hidrodinâmica da lagoa, a profundidade limite entre a deposição de areia e lama corresponde a aproximadamente $3 \mathrm{~m}$. Este resultado foi validado por dados texturais e batimétricos.

O desenvolvimento dos cordões de dunas frontais na planície de cordões litorâneos, da margem NE da Lagoa dos Quadros, resulta da importante ação dos ventos provenientes do quadrante SSW e SW cujas frequências e velocidades são superadas apenas pelo vento NE. Sedimentos relacionados às fases iniciais de formação dos campos de dunas transgressivos da barreira de Curumim (entre 7,1 e 5,5 ka) podem ter sido uma importante fonte de areia para a formação da planície de cordões litorâneos regressivos da margem NE da Lagoa dos Quadros.

Agradecimentos - Os autores agradecem ao PRH-PB 215 (Programa de Formação de Recursos Humanos em Geociências, no 215) pela bolsa de pesquisa e auxílio financeiro, ao CNPq pelo auxílio financeiro (Projeto Universal 484856/2011-1).

\section{Referências}

Angulo, R.J. \& Lessa, G.C. 1997. The Brazilian sea level curves: a critical review with emphasis on the curves from Paranaguá and Cananéia regions. Marine Geology, 140: 141-166.

Angulo, R.J., Giannini, P.C.F., Suguio, K. \& Pessenda, L.C.R. 1999. The relative sea-level changes in the last 5,500 years sourthern Brazil (Laguna-Imbituba region, Santa Catarina state) based on vermetid 14C ages. Marine Geology, 159(1/4): 327-339.

Angulo, R.J., Lessa, G.C. \& Souza, M.C. 2006. A critical review of the mid- to late Holocene sea-level fluctuations on the eastern Brazilian coastline. Quaternary Science Reviews, 25(5/6): 486-506.

Anthony, E.J. 2008. Shore processes and their palaeoenvironmental applications. Amsterdam, Elsevier, 540p.

Bagnold, R.A. 1941. The physics of blown sand and desert dunes. London, Chapman and Hall, 265p.

Barboza, E.G. 1999. Terraços da margem leste da laguna dos patos, litoral médio do rio grande do sul: estratigrafia e evolução holocênica. Porto Alegre, 154p. Dissertação de Mestrado, Programa de Pós-graduação em Geociências, Instituto de Geociências, Universidade Federal do Rio Grande do Sul.

Barboza, E.G. \& Tomazelli, L.J. 2003. Erosional features of the eastern margin of the Patos Lagoon, Southern Brazil: significance for holocene history. Journal of Coastal Research, SI 35: 260-264.

Barboza, E.G. \& Rosa, M.L.C.C. 2014. Indicadores geológicos e geomorfológicos de setores em erosão na costa do Rio Grande do Sul. In: Goso, C. (Ed.). Nuevas miradas a la problemática de los ambientes costeros sur de Brasil, Uruguay y Argentina. Montevideo, DIRAC, p. 83-98.

Barboza, E.G., Dillenburg, S.R., Rosa, M.L.C.C., Tomazelli, L.J. \& Hesp, P.A. 2009. Ground-penetrating radar profiles of two holocene regressive barriers in southern Brazil. Journal of Coastal Research, SI 56: 579-583.

Barboza, E.G., Rosa, M.L.C.C., Dillenburg, S.R., Tomazelli, L.J. \& Ayup-Zouain, R.N. 2011a. Comportamento regressivo/transgressivo da linha de costa na bacia de Pelotas durante o Holoceno médio e tardio. In: López, R.A \& Marcomini, S.C. (Ed.). Problemática de Los Ambientes Costeros. Buenos Aires, Croquis, p. 15-30.

Barboza, E.G., Rosa, M.L.C.C., Hesp, P.A., Dillenburg, S.R., Tomazelli, L.J. \& Ayup-Zouain, R.N. 2011b. Evolution of the holocene coastal barrier of Pelotas basin (southern Brazil) - a new approach with GPR data. Journal of Coastal Research, SI 64: 646-650.

Barboza, E.G., Rosa, M.L.C.C., Dillenburg, S.R \& Tomazelli, L.J. 2013. Preservation potential of foredunes in the stratigraphic record. Journal of Coastal Research, SI 65, 1265-1270.

Barboza, E.G., Rosa, M.L.C.C. \& Caron, F. 2014. Metodologia de Aquisição e Processamento em Dados de Georradar (GPR) nos Depósitos Quaternários da Porção Emersa da Bacia de Pelotas. In: SIMPÓSIO BRASILEIRO DE GEOFÍSICA,6 , Porto Alegre. Resumos Expandidos, v. 1. p. 1-6. 
Bendixen, M., Clemmensen, L.B. \& Kroon, A. 2013. Sandy berm and beach-ridge formation in relation to extreme sea-levels: a Danish exemple in a micro-tidal environment. Marine Geology, 344: 53-64.

Bennett, M.R., Cassidy, N.J. \& PILE, J. 2009. Internal structure of a barrier beach as revealed by ground penetrating radar (GPR): Chesil beach, UK. Geomorphology, 104: 218-229.

Biancini da Silva, A., Barboza, E.G., Rosa, M.L.C.C. \& Fracalossi, F.G. 2010. Caracterização dos depósitos sedimentares em subsuperfície no setor meridional da planície costeira sul de Santa Catarina. Gravel, 8: 1-7.

Biancini da Silva, A., Barboza, E.G., Rosa, M.L.C.C. \& Dillenburg, S.R. 2014. Meandering Fluvial System Influencing the Evolution of a Holocene Regressive Barrier in Southern Brazil. Journal of Coastal Research, SI 70: 205-210.

Billy, J., Robin, N., Hein, C.J., Certain, R. \& FitzGerald, D.M. 2014. Internal architecture of mixed sand-and-gravel beach ridges: Miquelon-Langlade Barrier, NW Atlantic. Marine Geology, 357: 53-71.

Bracco, R., del Puerto, L., Inda, H. \& Castiñeira, C. 2005. Middle-late Holocene cultural and environmental dynamics in the east of Uruguay. Quaternary International, 132: 37-45.

Bristow, C.S. \& Pucillo, K., 2006. Quantifying rates of coastal progradation from sediment volume using GPR and OSL: the Holocene fill of Guichen Bay, southeast South Australia. Sedimentology, 53: 769-788.

Bristow, C.S., Bailey, S.D. \& Lancaster, N. 2000a. The sedimentary structure of linear sand dunes. Nature, 406: 56-59.

Bristow, C.S., Chroston, P.N. \& Bailey, S.D., 2000b. The structure and development of foredunes on a locally prograding coast: insights from ground penetrating radar surveys, Norfolk, England. Sedimentology ,47: 923-944.

Cardoso, L., Silveira, A.L.L. \& Motta Marques, D.M.L. 2003. A ação do vento como gestor da hidrodinâmica na Lagoa Itapeva (litoral norte do Rio Grande do Sul). Revista Brasileira de Recursos Hídricos, 8(3): 5-15.

Caron, F., Lima, L.G., Dillenburg, S.R., Tomazelli, L.J., Barboza, E.G., Antiqueira, J.A.F., Rosa, M.L.C.C. Manzolli, R.P. \& Silva, A.B., 2010. Morphology, stratigraphy and factors controlling evolution of a transgressive barrier in southern Brazil. In: MEETING OF THE AMERICAS. Eos Trans. AGU, 2010, Foz do Iguaçu. Meet. Am. Suppl., v. 91. p. OS21A-01.

Carter, R.W.G. 1986. The morphodynamics of beachridge formation: Magilligan, Northern Ireland. $M a-$ rine Geology, 73: 191-214.

Choi, K.H., Choi, J.H. \& Kim, J.W. 2013. Reconstruction of Holocene coastal progradation on the east coast of Korea based on OSL dating and GPR surveys of beach-foredune ridges. The Holocene, 24(1): 24-34.

Clemmensen, L.B. \& Nielsen, L. 2010. Internal architecture of a raised beach ridge system (Anholt, Denmerk) resolved by ground-penetrating radar investigations. Sedimentary Geology, 223: 281-290.

Clerot, L.C.P. 2004. Estudo da barreira IV na região do
Cassino, Rio Grande - RS: evolução e caracterização como reservatório. Porto Alegre, 75p. Monografia de Conclusão de Curso, Curso de Geologia, Instituto de Geociências, Universidade Federal do Rio Grande do Sul.

Curray, J.R., Emmel, F.J. \& Crampton, P.J.S. 1969. Holocene history of a strand plain lagoonal coast, Nayarit, Mexico. In: UNAM-UNESCO (Ed.) Simposio Internacional, Lagunas Costeras. 1969. Ciudad del Mexico, UNESCO, p. 63-100.

Cwik, M.R. 1999. Aspectos físicos e sedimentológicos da Lagoa dos Quadros, litoral Norte do Rio Grande do Sul. Porto Alegre, 154p. Dissertação de Mestrado, Programa de Pós-graduação em Geociências, Instituto de Geociências, Universidade Federal do Rio Grande do Sul.

del Puerto, L., García-Rodríguez, F., Inda, H., Bracco, R., Castiñeira, C. \& Adams, J.B. 2006. Paleolimnological evidence of Holocene climatic changes in Lake Blanca, southern Uruguay. Journal of Paleolimnology, 36: 151-163.

Dillenburg, S.R. 1994. A Laguna de Tramandaí: evolução geológica e aplicação do método geocronológico da Termoluminescência na datação de depósitos sedimentares lagunares. Porto Alegre, 142p. Tese de Doutorado, Programa de Pós-graduação em Geociências, Instituto de Geociências, Universidade Federal do Rio Grande do Sul.

Dillenburg, S.R. \& Barboza, E.G. 2009. Long- and short term progradation of a regressive barrier in southern Brazil. Journal of Coastal Research, 56 (SI): 599-601.

Dillenburg, S.R. \& Barboza, E.G. 2014. The strike-fed sandy coast of Southern Brazil. Geological Society Special Publication, 388: 333-352.

Dillenburg, S.R., Tabajara, L.L.C.A. \& Toldo Jr., E.E. 1992. Dinâmica sedimentar e evolução geológica da Laguna de Tramandai-RS. In: CONGRESSO BRASILEIRO DE GEOLOGIA, 37, São Paulo, SBG, p. 15-19.

Dillenburg, S.R., Roy, P.S., Cowell, P.J. \& Tomazelli, L.J. 2000. Influence of antecedent topography on coastal evolution as tested by the Shoreface Translation-Barrier Model. Journal of Coastal Research, 16(1): 71-81.

Dillenburg, S.R., Tomazelli, L.J., Hesp, P.A., Barboza, E.G., Clerot, L.C.P. \& Silva, D.B. 2006. Stratigraphy and evolution of a prograded transgressive dunefield barrier in southern Brazil. Journal of Coastal Research, SI 39: 132-135.

Dillenburg, S.R., Barboza, E.G., Tomazelli, L.J., Hesp, P.A., Clerot, L.C.P. \& Ayup-Zouain, R.N. 2009. The Holocene coastal barriers of Rio Grande do Sul. In: Dillenburg, S.R. \& Hesp, P.A. (Ed.). Geology and Geomorphology of Holocene Coastal Barriers of Brazil. Berlin, Springer, p. 53-91.

Dillenburg, S.R., Barboza, E.G., Hesp, P.A. \& Rosa, M.L.C.C. 2011. Ground Penetrating Radar (GPR) and Standard Penetration Test (SPT) records of a regressive barrier in southern Brazil. Journal of Coastal Research, SI 64: 651-655.

Dillenburg, S.R., Barboza, E.G., Tomazelli, L.J., Rosa, M.L.C.C. \& Maciel, G. S. 2013. Aeolian Deposition 
and Barrier Stratigraphy of the Transition Region between a Regressive and a Transgressive Barrier: an example from Southern Brazil. Journal of Coastal Research, 65: 464-469.

Forsyth, A.J., Nott, J., Bateman, M.D. \& Beaman, R.J. 2012. Juxtaposed beach ridges and foredunes within a ridge plain - Wong Beach, northeast Australia. $\mathrm{Ma}$ rine Geology, 310: 111-116.

Fracalossi, F.G., Barboza, E.G., Rosa, M.L.C.C. \& Biancini da Silva, A. 2010. O Registro em Subsuperfície da Barreira Pleistocênica entre Osório e Tramandaí RS. Gravel, 8: 21-31.

Goy, J.Z., Zazo, C. \& Dabrio, C.J. 2003. A beach ridge complex reflecting periodical sea-level and climate variability during the Holocene (Gulf of Almeria, western Mediterranean). Geomorphology 50: 251-268.

Hallermeier, R. J. 1981. Critical wave conditions for sand motion initiation. Coastal Engineering Technical, 81(10), 16p.

Hasenack, H. \& Ferraro, L.W. 1989. Considerações sobre o clima da região de Tramandaí, RS. Pesquisas em Geociências, 22: 53-70.

Hesp, P.A. 1984. The formation of sand "beach ridges" and foredunes. Search, 15: 289-291.

Hesp, P.A. 1999. The Beach Backshore and Beyond. In Short, A.D. (Ed.). Handbook of Beach and Shoreface Morphodynamics, New York, John Wiley, p. 70-145.

Hesp, P.A. 2006. Sand beach ridges: Definition and re-definition. Journal Coastal Research, SI 39: 72-75.

Hesp, P.A., Dillenburg, S.R., Barboza, E.G., Tomazelli, L.J., Ayup-Zouain, R.N., Esteves, L.S., Gruber, N.L.S., Toldo Jr., E.E., Tabajara, L.L.C. \& Clerot, L.C.P. 2005. Beach ridges, foredunes or transgressive dunefields? Definitions and an examination of the Torres to Tramandaí barrier system, Southern Brazil. Anais da Academia Brasileira de Ciências, 77(3): 495-508.

Hesp, P.A., Dillenburg, S.R., Barboza, E.G., Clerot, L.C.P., Tomazelli, L.J. \& Ayup-Zouain, R.N. 2007. Morphology of the Itapeva to Tromandai transgressive dunefield barrier system and mid-to-late Holocene sea level change. Earth Surfaces and Landforms, 32: 407 414.

Hesp, P.A., Giannini, P.C.F., Martinho, T., Miot da Silva, G. \& Asp Neto, N.E. 2009. The Holocene barrier systems of the Santa Catarina Coast, Southern Brazil. In: Dillenburg, S.R. \& Hesp, P.A. (Ed.). Geology and Geomorphology of Holocene Coastal Barriers of Brazil. Berlin, Springer, p. 95-133.

Hofmann, H., Lorke, A. \& Peeters, F. 2008. Temporal scales of water-level fluctuations in lakes and their ecological implications. 2008. Hydrobiologia, 613: 85-96.

Horn Filho, N.O. 1988. Geologia das folhas de Torres, Três Cachoeiras, Arroio Teixeira e Maquiné, nordeste do Rio Grande do Sul. Revista Brasileira de Geociências, 18: 378-378.

Ivanoff, M.D. 2013. Sedimentação da Lagoa Itapeva, $R S$ - Brasil. Alegre, 56p. Dissertação de Mestrado, Programa de Pós-graduação em Geociências, Instituto de Geociências, Universidade Federal do Rio Grande do Sul.
Ivanoff, M.D., Toldo Jr., E.E. \& Figueira, E.C.L. 2014. Sedimentação da Lagoa Itapeva, RS, Brasil. Pesquisas em Geociências, 41(1): 3-13.

Johnston, J.W., Thompson, T.A. \& Baedke, S.J. 2007. Systematic pattern of beach-ridge development and preservation: conceptual model and evidence from ground penetrating radar. The Geological Society of America, special paper 432: 47-58.

Kochel, R.C. \& Wampfler, L.A. 1989. Relative Role of Overwash and Aeolian Processes on Washover Fans, Assateague Island, Virginia-Maryland. Journal of Coastal Research, 5(3): 453-475.

Komar, P.D. 1976. Beach Processes and Sedimentation. Englewood Cliffs, Prentice-Hall, 429p.

Leatherman, S.P. \& Zaremba, R.E. 1987. Overwash and Aeolian processes on a U.S. Northeast coast barrier. Sedimentary Geology, 52: 183-206.

Lima, L.G. 2012. Estratigrafia e evolução holocênica de uma barreira costeira transgressiva/regressiva, litoral norte do Rio Grande do Sul, Brasil. Porto Alegre. 128p. Tese de Doutorado, Programa de Pós-graduação em Geociências, Instituto de Geociências, Universidade Federal do Rio Grande do Sul.

Lima, L.G., Dillenburg, S.R., Medeanic, S., Barboza, E.G., Rosa, M.L.C.C., Tomazelli, L.J., Dehnhardt, B.A. \& Caron, F. 2013. Sea-level rise and sediment budget controlling the evolution of a transgressive barrier in southern Brazil. Journal of South American Earth Sciences, 42: 27-38.

Manzolli, R.P. 2011. Geomorfologia do complexo de cordões litorâneos lagunares do Pontal da Feitoria Margem Oeste-Sul da Laguna dos Patos. Porto Alegre, 90p. Dissertação de Mestrado, Programa de Pós-graduação em Geociências, Instituto de Geociências, Universidade Federal do Rio Grande do Sul.

Martinho, C.T., Dillenburg, S.R. \& Hesp, P.A. 2008. Mid to late Holocene evolution of transgressive dunefields from Rio Grande do Sul Coast, Southern Brazil. Marine Geology, 256: 49-64.

Martins, L.R., Villwock, J.A., Benvenutti, C.E. \& Martins, I.L.R. 1989. The Lagoa dos Patos Estuarine ecosystem RS, Brazil. Pesquisas, 22: 05-44.

Mauz, B., Hijma, M.P., Amorosi, A., Porat, N., Galili, E. \& Bloemendal, J. 2013. Aeolian beach ridges and Their Significance for climate and sea level: Concept and insight from the Levant coast (East Mediterranean). Earth-Science Reviews, 121: 3-54.

McKee, E. 1979. An introduction to the study of global sand seas. In: McKee, E. (Ed.). A Study of Global Sand Seas. Washington, U.S. Geological Survey Paper 1052, p. 1-20.

Medeanic, S. \& Dillenburg, S.R. 2005. Palynological records combined with $210 \mathrm{~Pb}$ dating: an integrated approach to estimate anthropogenic impact in the coastal environment of the Tramandaí lagoon and adjacent areas, RS, Brazil, during the last century. Journal of Coastal Research, 42: 265-270.

Medeiros, P.R.P. 1992. Estudo do Sistema Lagunar-Estuarino de Tramandaí-Imbé: Física e Química da Água. Porto Alegre, 112p. Dissertação de Mestrado, Programa de Pós-graduação em Ecologia, Instituto de 
Biociências, Universidade Federal do Rio Grande do Sul.

Meyer, K.E.B., Mendonça Filho, J.G., Ashraf, A.R., Souza, P.A. \& Reichhart, K. 2005. Análise de palinofácies em sedimentos holocênicos da Lagoa dos Quadros, Planície Costeira do Rio Grande do Sul, Brasil. Revista Brasileira de Paleontologia, 8(1): 57-72.

Meyer, K.E.B., Souza, P.A., Cwik, M.R., Menezes, T.R. \& Buchmann, F.S. 2006. Palinofácies e processos deposicionais em sedimentos de fundo da lagoa dos Quadros, Planície Costeira do Rio Grande do Sul, Brasil. Revista Brasileira de Geociências, 36: 623-622.

Mitchum Jr., R.M., Vail, P.R. \& Sangree, J.B. 1977. Seismic Stratigraphy and Global Changes of Sea Level, Part 6: Stratigraphy interpretation of seismic reflection patterns in depositional sequences. In: Payton, C.E. (Ed.). Seismic Stratigraphy - Applications to Hydrocarbon Exploration. Tulsa, AAPG 26, p. 117-133.

Moulton, M.A.B., Oliveira Filho, S., Rocha, T.B. \& Fernandez, G.B. 2013. Foredunes of Rio de Janeiro coast: genesis, structure and morphology. Journal of Coastal Research, SI 65: 1319-1324.

Neal, A., 2004. Ground-penetrating radar and its use in sedimentology: principles, problems and progress. Earth Science Reviews, 66: 261-330.

Neal, A., Pontee, N.I., Pye, K. \& Richards, J. 2002. Internal structure of mixed-sand-and-gravel beach deposits revealed using ground-penetrating radar. Sedimentology, 49: 789-804.

Nielsen, L.H. \& Johanessen, P.N. 2009. Facies architecture and depositional processes of the Holocene-Recent accretionary regressive Skagen spit system, Denmark. Sedimentology, 56: 936-968.

Otvos, E.G. 2000. Beach ridges-definitions and significance. Geomorphology, 32: 83-108.

Otvos, E.G. 2012. Coastal barriers - Nomenclature, processes, and classification issues. Geomorphology 139-140: 39-52.

Psuty, N. P. 1992. Spatial variation in coastal foredune development. In: Carter, R.W.G., Curtis, G.F. \& Sheehy-Skevfington, M. (Ed.). Coastal Dunes: Geomorphology, Ecology and Management. Balkema, The Hague, p. 3-13.

Reimer, P.J., Bard, E., Bayliss, A., Beck, J. W., Blackwell, P.G., Bronk Ramsey, C., Grootes, P.M., Guilderson, T.P., Haflidason, H., Hajdas, I., HattŽ, C., Heaton, T.J., Hoffmann, D.L., Hogg, A.G., Hughen, K.A., Ka APiser, K.F., Kromer, B., Manning, S.W., Niu, M., Reimer, R.W., Richards, D.A., Scott, E.M., Southon, J.R., Staff, R. A., Turney, C.S.M., \& van der Plicht, J. 2013. IntCal13 and Marine13 Radiocarbon Age Calibration Curves 0-50,000 Years cal BP. Radiocarbon, 55(4): 18691887.

Reinson, G.E. 1992. Transgressive barrier island and Estuarine systems. In: Walker, R.G. \& James, N.P. (Ed.). Facies models - response to sea level change. Stittsville, Geological Association of Canada, p. 179-194

Ritchie, W. \& Penland, S. 1988. Rapid dune changes associated with overwash processes on the deltaic coast of south Louisiana. Marine Geology, 81(1/4): 97-122.
Rocha, T.B., Fernandez, G.B., Peixoto, M.N.O. \& Rodrigues, A. 2013. Arquitetura deposicional e datação absoluta das cristas de praia pleistocênicas no complexo deltaico do Paraíba do Sul (RJ). Brazilian Journal of Geology, 43: 711-724.

Roy, P.S., Cowell, M.A., Ferland, M.A. \& Thom, B.G. 1994. Wave-dominated coasts. In: Carter, R.W.G. \& Woodroffe, C.D. (Ed.). Coastal Evolution - Late Quaternary Shoreline Morphodynamics. Cambridge, Cambridge University Press, p. 121-186.

Ruz, M.H. \& Meur-Ferec, C. 2004. Influence of high water levels on aeolian sand transport: upper beach/dune evolution on a macrotidal coast, Wissant Bay, northern France. Geomorphology, 60(1/2): 73-87.

Sanderson, P.G., Eliot, I. \& Fuller, M. 1998. Historical development of a Foredune plain at Desperate Bay, Wetern Australia. Journal of Coastal Research, 14(4): 1187-1201.

Santos, N.B., Lavina, E.LC. \& Paim, P.S.G. 2015. High-resolution stratigraphy of Holocene lagoon terraces of Southern Brazil. Quaternary Research, (83): 52-65.

Schwarzbold, A. \& Schäfer, A. 1984. Gênese e morfologia das Lagoas Costeiras do Rio Grande do Sul. Amazoniana, IX(1): 87-104.

Strahler, A.N. \& Strahler, A. H. 1987. Modern Physical Geography. New York, John Willey and Sons, 488p.

Tabajara, L.L. \& Dillenburg, S. R. 1997. Batimetria e Sedimentos de Fundo da Laguna de Tramandaí - RS. Notas Técnicas, 10: 21-33.

Tamura, T., Murakami, F., Nanayama, F., Watanabe, K. \& Saito, Y. 2008. Ground-penetrating radar profiles of Holocene raised-beach deposits in the Kujukuri strand plain, Pacific coast of eastern Japan. Marine Geology, 248: 11-27.

Tamura, T. 2012. Beach ridges and prograded beach deposits as palaeoenvironment records. Earth-Science Reviews, 114: 279-297.

Tanner, W.F. 1995. Origin of beach ridges and swales. Marine Geology, 129: 149-161.

Toldo Jr., E.E., Dillenburg, S.R., Corrêa, I.C.S. \& Almeida, L.E.S.B.. 2000. Holocene sedimentation in Lagoa dos Patos Lagoon, Rio Grande do Sul, Brazil. Jounal of Coastal Research, 16(3): 816-822.

Tomazelli, L.J. 1993. O regime de ventos e a taxa de migração das dunas eólicas costeiras do Rio Grande do Sul, Brasil. Pesquisas, 20(1): 18-26.

Tomazelli, L.J. \& Villwock, J.A. 1991. Geologia do Sistema Lagunar Holocênico do Litoral Norte do Rio Grande do Sul, Brasil. Pesquisas, 18(1): 13-24.

Tomazelli, L.J., Dillenburg, S.R., Barboza, E.G. \& Rosa, M.L.C.C. 2008. Geomorfologia e Potencial de Preservação dos Campos de Dunas Transgressivos de Cidreira e Itapeva, Litoral Norte do Rio Grande do Sul. Pesquisas em Geociências, 35: 47-55.

Tomazelli, L.J., Barboza, E.G., Rosa, M.L.C.C., Dillenburg, S.R., Caron, F., Manzolli, R.P. \& Lima, L.G. 2011. Terraços Lagunares Holocênicos da Margem da Lagoa do Gentil, Litoral Norte do Rio Grande do Sul: Gênese e Significado para a Evolução Geológica Regional. In: CONGRESSO DA ABEQUA, 13, Armação de Búzios, v. 1. p. $1356-1360$. 
Travessas, F.A., Dillenburg, S.R. \& Clerot, L.C.P. 2005. Estratigrafia e evolução da barreira holocênica do Rio Grande do Sul no trecho Tramandaí-Cidreira. Boletim Paranaense de Geociências, 57: 57-73.

USACE. 1984. SPM - Shore Protection Manual. Washington, U.S. Government Printing Office, 559p.

USACE. 2006. CEM - Coastal Engineering Manual. Washington, U.S. Government Printing Office, 2156p.

Vail, P.R., 1987. Seismic Stratigraphy Interpretation Using Sequence Stratigraphy. Part 1: Seismic Stratigraphy Interpretation Procedure. In: Bally, A.W. (Ed.). Atlas of Seismic Stratigraphy. Tulsa, AAPG, 27(1), p. 1-9.

Villwock, J.A. 1984. Geology of the coastal province of Rio Grande do Sul, Southern Brazil. A Synthesis. Pesquisas, 16: 5-49.

Man. 565

Editores: Carla Ennes Barros \& Maria do Carmo Lima e Cunha.
Villwock, J.A. \& Tomazelli, L.J. 1995. Geologia Costeira do Rio Grande do Sul. Notas Técnicas, 8: 1-45.

Weschenfelder, J., Corrêa, I.C. S., Aliotta, S. \& Baitelli, R. 2010. Paleochannels related to late Quaternary sea-level changes in Southern Brazil. Brazilian Journal of Oceanography, 58: 35-44.

Weschenfelder, J., Baitelli, R. Corrêa, I.C.S., Bortolin, E.C. \& Santos, C.B. 2014. Quaternary incised valleys in Southern Brazil coastal zone. Journal of South American Earth Sciences, 55: 83-93.

Woodroffe, C.D. 2002. Coasts, form, process and evolution. Cambridge, Cambridge University Press, 623p.

Woods, A.J.C. \& Leahy, L.P. 1983. Beach ridges and paleogeography, central Baja California, Mexico. Physical Geography, 4(3): 167-181. 
